\title{
SOLUBLE AND PELLETABLE FACTORS IN PORCINE, CANINE AND HUMAN NOTOCHORDAL CELL-CONDITIONED MEDIUM: IMPLICATIONS FOR IVD REGENERATION
}

\author{
F.C. Bach ${ }^{1, \S}$, S.A.H. de Vries ${ }^{2,}$, F.M. Riemers ${ }^{1}$, J. Boere ${ }^{3,4,5}$, F.W.M. van Heel $^{1}$, M. van Doeselaar ${ }^{2}$, S.S. Goerdayal ${ }^{6}$, \\ P.G.J. Nikkels ${ }^{7}$, K. Benz ${ }^{8}$, L.B. Creemers ${ }^{5}$, A.F. Maarten Altelaar ${ }^{6}$, B.P. Meij ${ }^{1}$, K. Ito $^{2,5}$ and M.A. Tryfonidou, ${ }^{1, *}$ \\ ${ }^{1}$ Department of Clinical Sciences of Companion Animals, Faculty of Veterinary Medicine, Utrecht University, \\ Utrecht, the Netherlands \\ ${ }^{2}$ Orthopaedic Biomechanics, Department of Biomedical Engineering, Eindhoven University of Technology, \\ Eindhoven, the Netherlands \\ ${ }^{3}$ Department of Biochemistry and Cell Biology, Faculty of Veterinary Medicine, Utrecht University, Utrecht, \\ the Netherlands \\ ${ }^{4}$ Department of Equine Sciences, Faculty of Veterinary Medicine, Utrecht University, Utrecht, the Netherlands \\ ${ }^{5}$ Department of Orthopaedics, University Medical Centre Utrecht, Utrecht, the Netherlands \\ ${ }^{6}$ Biomolecular Mass Spectrometry and Proteomics, Bijvoet Centre for Biomolecular Research, Utrecht Institute for \\ Pharmaceutical Sciences and The Netherlands Proteomics Centre, Utrecht University, Utrecht, the Netherlands \\ ${ }^{7}$ Department of Pathology, University Medical Centre Utrecht, Utrecht, the Netherlands \\ ${ }^{8}$ TETEC AG, Reutlingen, Germany
}

\$These authors contributed equally, shared first authorship.

\begin{abstract}
During intervertebral disc (IVD) maturation, notochordal cells (NCs) are replaced by chondrocyte-like cells (CLCs) in the nucleus pulposus, suggesting that NCs play a role in maintaining tissue health. Affirmatively, NC-conditioned medium (NCCM) exerts regenerative effects on CLC proliferation and extracellular matrix (ECM) production. The aim of this study was to identify NC-secreted substances that stimulate IVD regeneration. By mass spectrometry of porcine, canine and human NCCM, 149, 170 and 217 proteins were identified, respectively, with 66 proteins in common. Mainly ECM-related proteins were identified, but also organelle-derived and membranebound vesicle proteins. To determine whether the effect of NCCM was mediated by soluble and/or pelletable factors, porcine and canine NCCM were separated into a soluble (NCCM-S; peptides and proteins) and pelletable (NCCM-P; protein aggregates and extracellular vesicles) fraction by ultracentrifugation, and tested on bovine and canine CLCs in vitro, respectively. In each model, NCCM-S exerted a more pronounced anabolic effect than NCCM-P. However, glycosaminoglycan (GAG) uptake from the medium into the carrier gel prevented more definite conclusions. While the effect of porcine NCCM-P on bovine CLCs was negligible, canine NCCM-P appeared to enhance GAG and collagen type II deposition by canine CLCs. In conclusion, porcine and canine NCCM exerted their anabolic effects mainly through soluble factors, but also the pelletable NCCM factors showed moderate regenerative potential. Although the regenerative potential of NCCM-P should not be overlooked, future studies should focus on unraveling the protein-based regenerative mechanism from NCCM produced from isolated NCs, e.g. by NCCM fractionation and pathway blocking studies.
\end{abstract}

Keywords: Intervertebral disc degeneration, nucleus pulposus, notochordal cells, notochordal cell-conditioned medium, proteomics, extracellular vesicles, regenerative medicine, canine, porcine, human.

\author{
*Address for correspondence: \\ Marianna A. Tryfonidou \\ Department of Clinical Sciences of Companion Animals \\ Faculty of Veterinary Medicine \\ Utrecht University \\ Yalelaan 108 \\ 3584 CM Utrecht \\ the Netherlands
}

Telephone Number $+31-30-2534558$

FAX Number: +31-30-25184126

E-mail: m.a.tryfonidou@uu nl

\section{Introduction}

Low back pain in humans is associated with intervertebral disc (IVD) degeneration (Cheung et al., 2009; Luoma et al., 2000). The IVD consists of a hydrated nucleus pulposus (NP), mainly composed of proteoglycan (PG) and collagen type II, circumferentially confined by the annulus fibrosus (AF) in which collagen type I is most prominent. The PG's negative charges attract water into the NP, but its swelling is restricted by the AF. This gives rise to high osmotic pressure, crucial for sustaining compressive loads in the healthy IVD. IVD degeneration is a complex, multifactorial process and is characterised by replacement of proteoglycans and collagen type II by a fibrous and dysfunctional tissue high in collagen type I. Current treatment methods aim to alleviate pain without addressing the underlying mechanism of IVD degeneration. Therefore, 
cell- or growth factor-based regenerative strategies have gained increased attention (Bach et al., 2014; Benneker et al., 2014; Sakai and Grad, 2015; Sakai and Andersson, 2015). Although several regenerative strategies, e.g. allogeneic mesenchymal precursor cell (https:// clinicaltrials.gov/ct2/show/NCT01290367)/autologous disc chondrocyte (NCT01640457) transplantation or growth factor application (NCT00813813), have entered the clinical trial phase, no effective regenerative therapy for IVD degeneration is yet clinically available.

In the field of IVD regeneration, notochordal cells (NCs) have gained increasing interest because of their potential regenerative and protective properties (Purmessur et al., 2013). NCs are large, vacuolated cells and are only present in the NP of foetal and young human individuals. They disappear at approximately 10 years of age, leaving the chondrocyte-like cells (CLCs) as the primary cell type in the NP. This process precedes the onset of IVD degeneration, suggesting that NCs play a role in maintaining tissue health. The regenerative effect of NC-secreted factors present in NC-conditioned medium (NCCM) was demonstrated previously on CLCs (Abbott et al., 2012; Potier et al., 2014) and mesenchymal stem cells (MSCs) (de Vries et al., 2015; Korecki et al., 2010; Purmessur et al., 2011), with clear cross-species activity (Bach et al., 2015). Furthermore, porcine NCCM exerted a regenerative effect on bovine NP explants (de Vries et al., 2016), suggesting that NCCM can also stimulate cells in their native tissue.

The use of NCCM itself, however, is not a clinical option; only small volumes can be injected in the IVD, which is likely insufficient to induce a long-term regenerative response. Therefore, identification and subsequent synthetic production of the biologically active factors in NCCM is more appealing. Up to date, only few studies reported on the potential biologically active NCCM factors. Connective tissue growth factor (CTGF) was found in canine (Erwin et al., 2006) and porcine (Gantenbein et al., 2014) NCCM and alpha-2-macroglobulin, clusterin and tenascin were detected in porcine NCCM (Purmessur et al., 2011).

Initial identification of NCCM's active factors has focused on proteomics, but extracellular vesicles (EVs) have not been considered yet. EVs are a heterogeneous group of small, membrane-enclosed particles $(\sim 40 \mathrm{~nm}$ to $\sim 5 \mu \mathrm{m}$ ), actively released by cells from various tissue types (van der Vlist et al., 2012; Witwer et al., 2013). EVs play an active role in intercellular signalling, since they can express receptor ligands or can be vehicles of signalling molecules. Previous studies indicated that EVs influence various processes, such as pathogenesis of diseases (Anderson et al., 2010) and tissue regeneration (Malda et al., 2016). As such, it was hypothesised that EVs can also be secreted by NCs and may be involved in maintaining healthy NP tissue. The aim of the current study was to identify whether soluble (peptides and proteins) or pelletable (protein aggregates and EVs) factors are responsible for the anabolic effects of NCCM on CLCs. We hypothesised that both the soluble and pelletable factors contribute to the anabolic effects of NCCM.

\section{Materials and Methods}

\section{Sources of NC-rich NP tissue and generation of NCCM}

Thompson grade I IVDs were collected from 5 porcine, 16 canine and 3 human donors. Porcine spines ( 3 months of age, C1-S1) were collected from the local abattoir. Canine spines (16-38 months of age, C1-S1) were collected from mixed breed non-chondrodystrophic (NCD) dogs euthanised in unrelated research studies, approved by the Utrecht University Animal Ethics Committee. IVDs from human donors (L2-L5) between 20 weeks of gestation and 2 days of age (postnatal) were obtained during standard post mortem diagnostic procedures, approved by the scientific committee of the Pathology Department of the University Medical Centre Utrecht. Anonymous use of redundant tissue for research purposes is a standard treatment agreement with patients in the University Medical Centre Utrecht (Local Medical Ethical Committee (METC) number 12-364). The material was used in line with the code 'Proper Secondary Use of Human Tissue' installed by the Federation of Biomedical Scientific Societies.

\section{Generation of NCCM}

Conditioned medium from porcine $(n=5)$, canine $(n=8)$ and human $(n=3)$ NC-rich NP tissue $(\mathrm{NCCM}+)$ was generated by culturing NP tissue for $4 \mathrm{~d}(1 \mathrm{~g}$ tissue $/ 30 \mathrm{~mL})$ in hgDMEM+Glutamax (31966, Invitrogen, Paisley, UK) with $1 \%$ penicillin/streptomycin (P11-010, GE Healthcare Life Sciences, Eindhoven, the Netherlands) at $37{ }^{\circ} \mathrm{C}, 5 \% \mathrm{CO}_{2}$ and $5 \% \mathrm{O}_{2}$ (Bach et al., 2015) (Fig. 1a). After $4 \mathrm{~d}$, NP tissue was removed and NC-conditioned medium was filtered through $70 \mu \mathrm{m}$ cell strainers. The filtrate was sequentially centrifuged at $200 \times g$ and $500 \times g$ (two times $10 \mathrm{~min}, 4{ }^{\circ} \mathrm{C}$ ) to remove (dead) cells and debris. Thereafter, the supernatant (cell-free conditioned medium) was concentrated using a $3 \mathrm{kDa}$ Amicon Ultra-15 Centrifugal filter tube (Merck Millipore, Amsterdam, the Netherlands) at $4000 \times g\left(45 \mathrm{~min}, 4^{\circ} \mathrm{C}\right)$. All substances with a molecular weight $>3 \mathrm{kDa}$ were resuspended in fresh hgDMEM+Glutamax and stored in aliquots at $-70{ }^{\circ} \mathrm{C}$ until use. To determine whether the porcine and canine $\mathrm{NCCM}+$ effects were $\mathrm{NC}$-specific, negative control conditioned media $(\mathrm{NCCM}-)$ were generated by re-culturing the NP tissue in the presence of $5 \%$ foetal bovine serum (FBS, Gibco 16000-044, Life Technologies, Bleiswijk, the Netherlands); the latter results in loss of vacuolatedNC morphology (Arkesteijn et al., 2013). NP tissue was cultured for $18 \mathrm{~d}$ with medium changes twice a week, until no more vacuoles were observed. Subsequently, the NP tissue was washed twice to remove FBS components, and cultured for $4 \mathrm{~d}$ in hgDMEM+Glutamax with $1 \% \mathrm{P} / \mathrm{S}$ to generate $\mathrm{NCCM}-$. NCCM- was centrifuged, filtered and stored similar to $\mathrm{NCCM}+$.

\section{Proteomic analysis of porcine, canine and human NCCM}

$\mathrm{NCCM}+$ from 5 porcine, 5 canine and 3 human donors were deglycosylated overnight at $37{ }^{\circ} \mathrm{C}$ with $20 \mathrm{U}$ PGNaseF (V4831, Promega, Madison, WI, USA). Protein digestion 


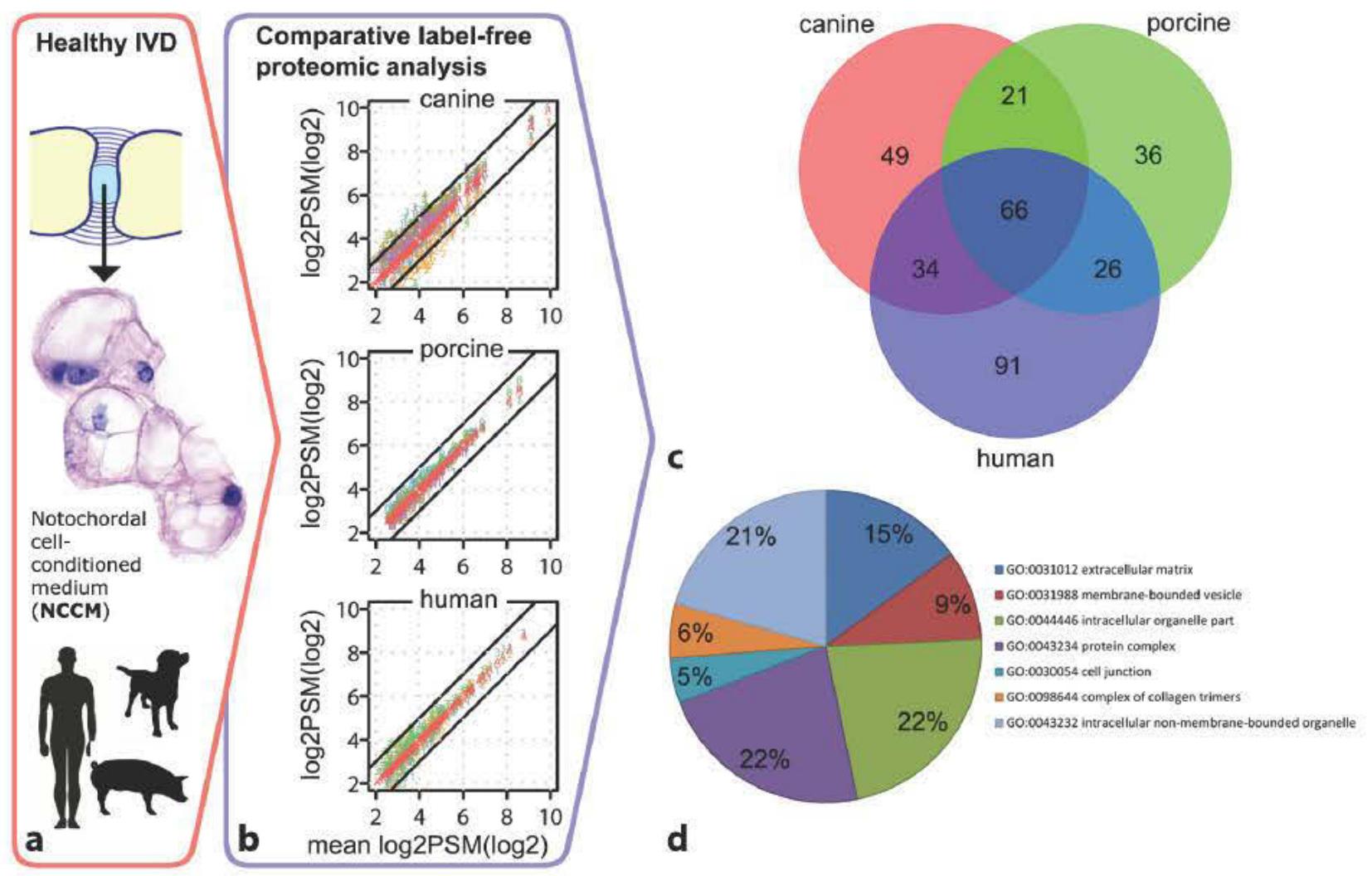

Fig. 1. Proteomic analysis of porcine, canine and human notochordal cell (NC)-conditioned medium (NCCM). (a) NCCM was generated from NC-rich nucleus pulposus (NP) tissue of porcine $(n=5)$, canine $(n=5)$ and human $(n=3)$ donors. (b) $\log 2$ values of the number of peptide spectrum matches (PSM) plotted against the average number of PSMs for each protein show a higher inter-donor variability for canine NCCM than for porcine and human NCCM. (c) The number of proteins discovered in porcine, canine and human NCCM, and their combinations. (d) Cell and/ or matrix origins of the 66 proteins in common to all three species NCCM.

was performed with filter aided sample preparation (FASP) (Wisniewski et al., 2009) with a buffer containing $8 \mathrm{M}$ urea in $1 \mathrm{mM}$ Tris- $\mathrm{HCl}$ at $\mathrm{pH} 8.0$ and $\mathrm{pH} 8.5$; using filters with cut off of $10 \mathrm{kDa}$ (MRCPRT010, YM-10, Microcon, Merck Millipore). Proteins were reduced with $10 \mathrm{mM}$ dithiothreitol (43815, Sigma-Aldrich, Saint Louis, MO, USA), alkylated with $200 \mathrm{mM}$ iodoacetamide (I625-5G, Sigma-Aldrich), and digested first for $4 \mathrm{~h}$ with $2 \mathrm{mg} / \mathrm{mL}$ LysC (Lysyl Endopeptidase, 129-02541, Wako Chemicals, Richmond, VA, USA) in a ratio of 1:50 and then overnight with $0.1 \mu \mathrm{g} / \mu \mathrm{L}$ trypsin (V5280, Promega) in a ratio of 1:50. The digested samples were desalted using Oasis HLB 96 well $\mu$ elution plate (186001828BA, Waters, Etten-Leur, the Netherlands). Finally, samples were dried and reconstituted in $40 \mu \mathrm{L}$ of $10 \%$ formic acid $/ 5 \%$ dimethyl sulphoxide.

Reversed phase nLC-MSMS analysis was performed using a Proxeon EASY-nLC 1000 (Thermo Scientific, Breda, the Netherlands) (de Graaf et al., 2014). Mass spectra were acquired using a Q-Exactive Plus mass spectrometer (Thermo Scientific) (Marino et al., 2014) at a resolution of 35,000 with a scan range from 375 to $1600 \mathrm{~m} / \mathrm{z}$. Dynamic exclusion was set at $10 \mathrm{~s}$. Raw data files were analysed using Proteome Discoverer (version 1.4.1.14, Thermo Scientific) (Marino et al., 2014). Data were searched against the SwissProt version 2014-12 for Sus scrofa, Canis familiaris or Homo sapiens.

Protein profile analysis was performed with $\mathrm{R}$ version 3.2.2 (developed by the R Core Team, 2015), using
preprocessCore (Bolstad, 2016), biomaRt (Durinck et al., 2009) and VennDiagram (Chen, 2015) packages. For each species, the obtained peptide spectrum match (PSM) values were filtered for each protein on missing or low values. For canine and porcine, the sum of the PSM values for any protein was set at $>5$ for at least 4 out of 5 samples and for human, the sum was set at $>4$ for at least 2 out of 3 samples. The PSM values of filtered proteins were log transformed and quantile normalised. Each sample was plotted against the species mean to assess data distribution (Fig. 1). To compare the profiles of the different species, filtered proteins were given a HGNC gene name using the Uniprot, Ensembl and HGNC databases and annotation results were manually curated. Per species, gene name lists were compared using a venn diagram and the different overlapping sets were analysed using toppgene (ToppFun) analysis (Chen et al., 2009). Enriched GO Cellular Component terms were remapped to common ancestors within the GO Cellular Component term using GO.db version 3.2.2 (Carlson, 2016).

\section{Separation of the soluble and pelletable NCCM fraction}

To unravel whether the biologically active factors in $\mathrm{NCCM}+$ were present in the soluble (NCCM-S) or pelletable (NCCM-P) fraction, ultracentrifugation was performed (van der Vlist et al., 2012). $37 \mathrm{~mL}$ porcine or canine NCCM was ultracentrifuged at $10,000 \times \mathrm{g}$ (30 min, 
$8,700 \mathrm{rpm}$; RCF average $10,016 \times \mathrm{g}$; RCF $\max 13,648 \times g$; $\kappa$-factor 2543.1) and 100,000 $\times g(65 \mathrm{~min}, 23,000 \mathrm{rpm}$; RCF average $70,002 \times g$; RCF $\max 95,389 \times g$; $\kappa$-factor 363.9$)$ at $4{ }^{\circ} \mathrm{C}$ (Beckman Coulter Optima L-90K ultracentrifuge, SW28 rotor). After $100,000 \times g$ ultracentrifugation, the supernatant containing soluble factors (NCCM-S) was aliquoted and stored at $-70{ }^{\circ} \mathrm{C}$ until use. The $100,000 \times g$ pellet, containing EVs and protein aggregates, was suspended in $246 \mu \mathrm{L}$ phosphate-buffered saline (PBS) supplemented with $0.2 \% \mathrm{EV}$-free bovine serum albumin (BSA, A9418, Sigma-Aldrich) $(6.7 \mu \mathrm{L} \mathrm{PBS} / 0.2 \%$ BSA per $\mathrm{mL} \mathrm{NCCM}$ ) and stored at $-70^{\circ} \mathrm{C}$ until use. The PBS $/ 0.2 \%$ BSA was depleted from EVs by ultracentrifugation overnight at $100,000 \times \mathrm{g}$. Directly prior to use for culture, aliquots of the pelletable factors (dissolved in PBS $/ 0.2 \%$ BSA) were thawed rapidly for maximal functional preservation (Witwer et al., 2013). Thereafter, in order to yield NCCM-P, $6.7 \mu \mathrm{L}$ of the $100,000 \times g$ pellet was added to $1 \mathrm{~mL}$ basal culture medium (hgDMEM+Glutamax with $1 \% \mathrm{P} / \mathrm{S}, 1 \%$ ITS + premix (354352, Corning Life Sciences, Amsterdam, the Netherlands), $0.04 \mathrm{mg} / \mathrm{mL}$ L-proline (P5607, Sigma-Aldrich), $0.1 \mathrm{mM}$ ascorbic acid 2-phosphate, and $1.25 \mathrm{mg} / \mathrm{mL}$ BSA. The EV content of NCCM-P was hereby similar to NCCM+.

\section{Biochemical analysis of NCCM and its fractions}

The protein concentration of $\mathrm{NCCM}+, \mathrm{NCCM}-, \mathrm{NCCM}-\mathrm{S}$ and NCCM-P (porcine $n=4$, canine $n=8$ ) was assessed using the Qubit ${ }^{\circledR}$ Protein Assay Kit (Q33211, Invitrogen) according to the manufacturer's instructions. In addition, a dimethyl methylene blue (DMMB) assay (Farndale et al., 1982) was performed to determine the glycosaminoglycan (GAG) concentration.

\section{In vitro culture of bovine and canine CLCs in pelletable and soluble fractions of NCCM}

Bovine CLCs $(n=4$ repeats, CLCs from 2 donors pooled per repeat, 2-2.5 years of age, Thompson grade II) were harvested from caudal IVDs obtained from the local abattoir, and chondrodystrophic (CD) canine CLCs $(n=4$, 3-10 years of age, Thompson grade III) were harvested from IVDs of dogs euthanised in unrelated research studies, approved by the Utrecht University Animal Ethics Committee. NPs were enzymatically digested with $0.1 \%$ pronase (10165921001, Roche Diagnostics, Almere, the Netherlands) for 90 min and subsequently with $0.025 \%$ collagenase type II (LS004177, Worthington, Lakewood, NJ, USA) for $16 \mathrm{~h}$ at $37{ }^{\circ} \mathrm{C}$.

Bovine CLCs were suspended in $1.2 \%$ alginate (180947, Sigma-Aldrich) beads of approximately $20 \mu \mathrm{L}$ at $3 \times 10^{6}$ cells $/ \mathrm{mL}$ (Guo et al., 1989). Empty (no cellcontaining) and CLC-containing beads were cultured for $28 \mathrm{~d}$ at $37{ }^{\circ} \mathrm{C}, 5 \% \mathrm{CO}_{2}$ and $5 \% \mathrm{O}_{2}$ in basal medium or in porcine NCCM+, NCCM-, NCCM-S or NCCM-P (four different porcine NCCM donors), each with the same supplements as basal culture medium.

Given that canine CLCs did not thrive in alginate beads (Arkesteijn et al., 2015), an albumin-based hydrogel was used (Scholz et al., 2010). Canine CLCs from four donors were pooled to assess the effect of donor-specific NCCM on a representative canine CLC population.
Passage 2 CLCs were incorporated in $40 \mu \mathrm{L}$ hydrogels composed of chemically activated albumin cross-linked by polyethylene glycol spacers (Benz et al., 2012) $\left(3 \times 10^{6}\right.$ cells $/ \mathrm{mL}$ hydrogel). The albumin- and hyaluronic acidcontaining hydrogels were cultured for $28 \mathrm{~d}$ at $37{ }^{\circ} \mathrm{C}, 5 \%$ $\mathrm{CO}_{2}$ and $5 \% \mathrm{O}_{2}$ in basal culture medium with/without $10 \mathrm{ng} / \mathrm{mL}$ transforming growth factor- $\beta_{1}$ (TGF- $\beta_{1}$ 240-B, R\&D Systems, Minneapolis, MN, USA), or in canine $\mathrm{NCCM}+, \mathrm{NCCM}-, \mathrm{NCCM}-\mathrm{S}$ or NCCM-P (eight different canine NCCM donors), each with the same supplements as basal medium. Unlike bovine CLCs, canine CLCs do not produce a considerable amount of GAGs if no growth factor is supplemented to the culture medium. Therefore, a positive control $\left(10 \mathrm{ng} / \mathrm{mL}\right.$ TGF- $\left.\beta_{1}\right)$ was used to show that the canine CLC donors were able to produce GAGs if a proper stimulus was provided, e.g. in case these donors would not respond to NCCM. Since the hydrogel bound GAGs present in NCCM, empty hydrogels were cultured along for each NCCM-/NCCM+/NCCM-S/NCCM-P donor to be able to correct for this.

Gene expression profiling (RT-qPCR; canine $n=8$ ) was performed at day 4, the DNA content (dsDNA High Sensitivity Assay Kit, Q32851, Invitrogen) and GAG content (DMMB assay; porcine NCCM-treated bovine CLCs $n=4$ and canine NCCM-treated canine CLCs $n=8$ in duplo) were determined at days 0 and 28 , and Safranin O/Fast Green staining and collagen type I and II immunohistochemistry (porcine NCCM-treated bovine CLCs $n=3-4$ and canine NCCM-treated canine CLCs $n=4-8$ ) were performed at day 28 (Bach et al., 2015). For gene expression profiling, four reference genes (GAPDH, HPRT, RPS19 and SDHA) were chosen to normalise gene expression of the target genes ACAN, ADAMTS5, BAX, BCL-2, CASP3, COL1A1, COL2A1, COL10A1, CCND1, FOXF1, KRT8, KRT18, KRT19, MMP13, T and $V E G F$. Primer sequences are depicted in Table 1. The DMMB assay was done with the following modifications: papain and DMMB solution $\mathrm{pH}$ was adjusted to 6.8 and guanidinium chloride was used to mask hyaluronic acid.

\section{Testing fresh versus frozen pelletable NCCM factors in vitro}

To determine whether freezing the pelletable factors affected their biological effect, micro-aggregates of 35,000 CD canine CLCs were generated (Bach et al., 2015). CLCs have more easy access to the pelletable factors in this culture model compared with hydrogels. The micro-aggregates were cultured in low-adherence 96-well plates $\left(650970\right.$, CELLSTAR ${ }^{\circledR}$, Greiner Bio-one, Alphen a/d Rijn, the Netherlands) at $37^{\circ} \mathrm{C}, 5 \% \mathrm{CO}_{2}$ and $5 \% \mathrm{O}_{2}$ for $7 \mathrm{~d}$ and were treated with basal culture medium (control), freshly generated, non-frozen NCCM-P (P1x fresh; kept at $4{ }^{\circ} \mathrm{C}$ for maximum $4 \mathrm{~d}$ ) or canine NCCM-P that was frozen at $-70{ }^{\circ} \mathrm{C}$ for maximum $4 \mathrm{~d}$ ( $\mathrm{P} 1 \mathrm{x}$ frozen). To determine whether a higher concentration pelletable factors would exert a more pronounced effect, fresh and frozen pelletable factors were also applied in a $10 \times$ higher concentration than present in $\mathrm{NCCM}+(\mathrm{NCCM}-\mathrm{P} 10 \times$ fresh and NCCM-P10 $\times$ frozen, respectively). The same CD canine CLC donors as used in the hydrogel experiment and 4 different NCD canine NCCM donors were used for 
Table 1. Primers used for quantitative PCR of canine samples.

\begin{tabular}{|c|c|c|c|c|c|}
\hline Genes & Forward sequence 5 , $\rightarrow 3$, & Reverse sequence $5^{\prime} \rightarrow 3$, & $\begin{array}{c}\text { Amplicon } \\
\text { size }\end{array}$ & $\begin{array}{l}\text { Annealing } \\
\text { temp }\left({ }^{\circ} \mathrm{C}\right)\end{array}$ & Accession no. \\
\hline \multicolumn{6}{|l|}{$\begin{array}{l}\text { Reference } \\
\text { genes }\end{array}$} \\
\hline GAPDH & TGTCCCCACCCCCAATGTATC & CTCCGATGCCTGCTTCACTACCTT & 100 & 58 & NM_001003142 \\
\hline HPRT & AGCTTGCTGGTGAAAAGGAC & TTATAGTCAAGGGCATATCC & 104 & 58 & NM_001003357 \\
\hline RPS19 & CCTTCCTCAAAAAGTCTGGG & GTTCTCATCGTAGGGAGCAAG & 95 & 61 & XM_005616513 \\
\hline SDHA & GCCTTGGATCTCTTGATGGA & TTCTTGGCTCTTATGCGATG & 92 & 56.5 & XM_535807 \\
\hline \multicolumn{6}{|l|}{$\begin{array}{l}\text { Target } \\
\text { genes }\end{array}$} \\
\hline$A C A N$ & GGACACTCCTTGCAATTTGAG & GTCATTCCACTCTCCCTTCTC & 111 & 62 & XM_005618252 \\
\hline ADAMTS5 & CTACTGCACAGGGAAGAG & GAACCCATTCCACAAATGTC & 149 & 61 & XM_846025.3 \\
\hline$B A X$ & CCTTTTGCTTCAGGGTTTCA & CTCAGCTTCTTGGTGGATGC & 108 & 58 & NM_001003011.1 \\
\hline$B C L 2$ & TGGAGAGVGTCAACCGGGAGATGT & AGGTGTGCAGATGCCGGTTCAGGT & 87 & 62 & NM_001002949 \\
\hline CASP3 & ATCACTGAAGATGGATGGGTTGGGTT & TGAAAGGAGCATGTTCTGAAGTAGCACT & 139 & 58 & NM_001003042 \\
\hline COL1AI & GTGTGTACAGAACGGCCTCA & TCGCAAATCACGTCATCG & 109 & 61 & NM_001003090 \\
\hline COL2AI & GCAGCAAGAGCAAGGAC & TTCTGAGAGCCCTCGGT & 151 & 62 & XM_005636674 \\
\hline COL10AI & CCAACACCAAGACACAG & CAGGAATACCTTGCTCTC & 80 & 61 & XM_003639401.2 \\
\hline$C C N D 1$ & GCCTCGAAGATGAAGGAGAC & CAGTTTGTTCACCAGGAGCA & 117 & 60 & NM_001005757.1 \\
\hline FOXFI & GAGTTCGTCTTCTCCTTCAACAC & GCTTGATGTCTTGGTAGGTGAC & 99 & 60 & XM_546792.5 \\
\hline KRT8 & CCTTAGGCGGGTCTCTCGTA & GGGAAGCTGGTGTCTGAGTC & 149 & 63 & XM_543639 \\
\hline KRT18 & GGACAGCTCTGACTCCAGGT & AGCTTGGAGAACAGCCTGAG & 97 & 60 & XM_534794 \\
\hline KRT19 & GCCCAGCTGAGCGATGTGC & TGCTCCAGCCGTGACTTGATGT & 86 & 64 & NM_001253742 \\
\hline$M M P 13$ & CTGAGGAAGACTTCCAGCTT & TTGGACCACTTGAGAGTTCG & 250 & 65 & XM_536598 \\
\hline$T$ & AGACAGCCAGCAATCTG & TGGAGGGAAGTGAGAGG & 115 & 53 & NM_001003092.1 \\
\hline$V E G F$ & CTTTCTGCTCTCCTGGGTGC & GGTTTGTGCTCTCCTCCTGC & 101 & 58 & NM_001003175 \\
\hline
\end{tabular}

All primers were designed in-house using Perlprimer except for MMP13 (Muir et al., 2005) and BAX (Mahmoudabady et al., 2013). Abbreviations used: GAPDH, glyceraldehyde 3-phosphate dehydrogenase; HPRT, hypoxanthine-guanine phosphoribosyltransferase; RPS19, ribosomal protein S19; SDHA, succinate dehydrogenase subunit A; $A C A N$, aggrecan, $A D A M T S 5$, a disintegrin and metalloproteinase with thrombospondin motifs 5; $B A X$, Bcl2-like-protein; $B C L-2$, B-cell CLL/lymphoma 2; CASP3, caspase-3; COL1A1, collagen type I; COL2A1, collagen type II; COL10A1, collagen type X; $C C N D 1$, cyclin D1; FOXF1, forkhead box F1; KRT8, keratin 8; KRT18, keratin 1; KRT19, keratin 19; MMP13, matrix metalloproteinase $13 ; T$, brachyury; $V E G F$, vascular endothelial growth factor.

this part of the study. Gene expression profiling (RT-qPCR; $n=8$ ) was performed at day 4 and the DNA and GAG contents of the micro-aggregates $(n=8)$ were determined at day 7 as described above.

\section{Statistical analysis of cell culture experiments}

Statistical analyses were performed using IBM SPSS statistics 22. Data were examined for normal distribution using a Shapiro Wilks test. Kruskal Wallis and MannWhitney $U$ test were performed on non-normally distributed data and one-way ANOVA on normally distributed data. Benjamini \& Hochberg False Discovery Rate post-hoc tests were performed to correct for multiple comparisons. In all tests, a $p$-value $<0.05$ was considered significant.

\section{Results}

\section{Proteomic analysis of porcine, canine and human $\mathrm{NCCM}+$}

$\mathrm{NCCM}+$ from 5 porcine, 5 canine and 3 human donors was subjected to mass spectrometry and bioinformatic analysis. $\log 2$-values of the number of PSMs plotted against the $\log 2$-values of the mean PSM number for each protein showed a wider distribution for canine NCCM, indicating a higher inter-donor variability than porcine and human NCCM (Fig. 1b). Raw pre-filtered protein profiles for porcine, canine and human NCCM contained, respectively, 737, 847 and 779 Uniprotids of which 153, 178 and 217 were left after filtering. These were annotated to 149,170 and 217 different HGNC gene names for porcine, canine and human, respectively, and were used for profile comparisons (Table 2). The three species had 66 of these proteins in common. A large fraction of the proteins was derived from organelles (22\%, Fig. 1) and macromolecular protein complexes ( $24 \%$ ). Furthermore, a considerable amount of extracellular matrix (ECM) (16\%) and membrane-bound vesicle proteins (10\%) were found in NCCM from all species.

Pathway analysis (Reactome, V55) of all common proteins revealed various processes involved in ECM and its structure (Table 3). The GAG-, collagen-, hyaluronic acid- and integrin-binding pathways were significantly covered, as well as the structural molecule activity and protein complex binding pathways. Other detected pathways contained growth factor- and enzyme-binding proteins.

Due to the presence of specific collagens (e.g. types III, $\mathrm{V}$ and $\mathrm{XV}$ ) in porcine and human, but not in canine NCCM, pathways involved in the assembly of collagen fibrils, biosynthesis and formation were significantly covered 
Table 2. Proteins identified in canine, porcine and human NCCM.

\begin{tabular}{|c|c|c|c|c|}
\hline Canine & Porcine & Human & Number & Proteins \\
\hline Yes & Yes & Yes & 66 & $\begin{array}{l}\text { ACAN, FN1, KRT8, COMP, COL6A3, CA3, ALB, VIM, CLU, KRT19, A2M, HSPG2, CHAD, } \\
\text { ABI3BP, XYLT1, ENO1, KRT18, CILP, PKM, COL6A1, COL2A1, EFEMP1, LAMB2, HAPLN1, } \\
\text { ACTN4, CLEC3A, RNASE4, TPI1, ACTN1, ACTC1, EHD2, LMNA, LAMA4, SERPINE2, } \\
\text { CILP2, PRELP, LAMC1, CSPG4, COL11A2, HTRA1, CD109, LDHA, ENO3, VCAN, HBB, } \\
\text { NID2, QSOX1, PRDX1, ANXA2, LGALS1, FMOD, KRT15, UGP2, PRDX6, PEBP1, YWHAE, } \\
\text { YWHAZ, EEF1A1, TUBB4B, RARRES2, THBS4, CHRDL2, ALDOC, PLOD1, MATN2, } \\
\text { YWHAG }\end{array}$ \\
\hline No & Yes & Yes & 26 & $\begin{array}{l}\text { AEBP1, ANXA1, ANXA5, ACTB, CLEC3B, COL11A1, COL15A1, COL3A1, COL5A1, } \\
\text { COL5A2, COL6A2, DPYSL2, EZR, GDI1, FBLN7, MSN, PCOLCE, PFN1, PGAM1, PPIA, } \\
\text { PYGL, SERPINB1, SERPINF1, SOD1, TNXB, VCL }\end{array}$ \\
\hline Yes & No & Yes & 34 & $\begin{array}{l}\text { TF, APOE, GAPDH, TNC, SERPINA1, SPTAN1, PGK1, GPI, LUM, LYZ, PRG4, DCN, ENO2, } \\
\text { ALDOA, SERPINA3, HBA1, GSN, EDIL3, MFGE8, HIST4H4, LGALS3, FBLN1, HSPA8, DES, } \\
\text { BGN, SPARC, TGFBI, HSP90AA1, CLSTN1, MDH1, CFH, FRZB, TKT, YWHAB }\end{array}$ \\
\hline No & No & Yes & 91 & $\begin{array}{l}\text { COL14A1, COL12A1, THBS1, HBG2, HBG1, PDIA3, IGHG1, THBS3, C4B, PPIB, POTEE, } \\
\text { RNASE1, MATN4, CALM1, COL9A1, COL1A1, OGN, SSC5D, IGKC, KRT1, PRDX2, COL1A2, } \\
\text { HBD, MATN3, P4HB, CFD, MMP3, EMILIN1, ANG, NUCB1, CAPG, C1S, ACTBL2, IGHG3, } \\
\text { SPTBN1, FABP4, ITIH5, COL16A1, APOH, UBC, YWHAQ, IGHG2, C1R, IGHG4, LOXL2, VIT, } \\
\text { B2M, CKM, ECM1, SERPINA5, KRT10, TUBA1B, FGFBP2, FBN1, DBI, PRDX4, TUBB2A, } \\
\text { CLEC11A, RCN1, GSTP1, HSPA1B, CA1, FNDC1, KRT7, HNRNPA2B1, HNRNPA1, C3, KRT9, } \\
\text { SELENBP1, FSTL1, HAPLN3, PGM1, FGA, FABP5, CALU, SLPI, HSP90B1, IQGAP1, TP5313, } \\
\text { RCN3, FBLN2, FLNA, MXRA5, TMSB4X, S100A10, CAT, HSP90AB1, DSC3, FSCN1, LRP1, } \\
\text { CYCS }\end{array}$ \\
\hline Yes & Yes & No & 21 & $\begin{array}{l}\text { SEMA3C, ENPP2, CP, CCL16, PCOLCE2, CCDC80, unchar1, APP, THY1, EHD3, KRT75, } \\
\text { KRT14, SMOC1, ACTN2, TPM1, LECT2, unchar2, HSPA2, TUBB, TUBB2B, TIMP2 }\end{array}$ \\
\hline No & Yes & No & 36 & $\begin{array}{l}\text { AHNAK, ANXA8, LOC100157318, CFB, SERPING1, C4A, CAPN2, CHADL, CHI3L1, } \\
\text { FLNC, HBQ1, H2BFS, HSPB1, KRT5, LOC100626701, ORM1, HIST2HBE, LOC102164134, } \\
\text { LOC100524210, MFI2, MYH9, NME2, NPEPPS, PFKL, PRKCDBP, RDX, LOC100736872, } \\
\text { SERPINA3-3, SPARCL1, SPP1, LOC100049693, TPM4, VAT1, SEMA7A, unchar3, H3F3A }\end{array}$ \\
\hline Yes & No & No & 49 & $\begin{array}{l}\text { CDH1, SLIT3, OLFML2B, PGAM4, CA2, KRT13, LGALS3BP, SOD3, ANOS1, LOC477441, } \\
\text { MB, MRC2, LTF, col11a2, MFAP4, TNFRSF11B, HSPA1A, LOC100855540, LDHB, NCAM1, } \\
\text { CHST3, LOC476825, LOXL3, KRT17, LOC100855471, TIMP3, CRYAB, CKB, SEMA3E, CFL1, } \\
\text { LOC488254, HSPA5, CCL21, HIST1H2AH, PTRF, CSTB, LECT1, CHST6, PGAM2, TUBA1A, } \\
\text { SLC2A1, TUBB4A, CDH2, HIST1H1C, FHL1, SDCBP, KRT78, GSTM3, EFEMP2 }\end{array}$ \\
\hline
\end{tabular}

by proteins present in human and porcine NCCM (Table 4). Also, proteins from platelet-involved pathways were found in these two species (Table 4). Analysis of proteins common in human and canine NCCM demonstrated pathways related to glucose metabolism (Table 5). Furthermore, due to the presence of decorin and biglycan, dermatan sulphate and chondroitin sulphate biosynthesis pathways were significantly covered in human and canine NCCM (Table 5). Both canine and porcine NCCM (Table 6) contained proteins involving tubulin-related pathways. Furthermore, several pathways with proteins present in only human, porcine or canine NCCM were detected (Tables 7-9). In porcine (Table 7) and human NCCM (Table 9), proteins related to complement binding pathways were detected. Lastly, proteins from axon guidance-related pathways were present in NCCM from all species (Tables 4 and 8).

A significant number of proteins involved with transcription factor (e.g. activator protein 1 (AP-1) and paired box gene 4 (PAX4)) binding sites were found in NCCM from all species (Table 10). Furthermore, proteins (predicted to be) targeted by miRNA29 were found in human and porcine NCCM (Table 11).

\section{In vitro culture of bovine $\mathrm{CLCs}$ in porcine $\mathrm{NCCM}$}

Porcine NCCM and its fractions were analysed for their protein and GAG concentration (Fig. 2a). NCCM-S contained a similar protein concentration as $\mathrm{NCCM}+$, whereas the protein concentration of NCCM-P was significantly lower than that of NCCM+, NCCM-S and
NCCM- $(p<0.05)$. The NCCM- protein concentration was significantly lower than that of $\mathrm{NCCM}+(p<0.05)$. Also the GAG concentration of NCCM+ and NCCM-S was comparable, and both were significantly higher than that of NCCM-P and NCCM- $(p<0.05)$. Although few GAGs were present in $\mathrm{NCCM}-$, its $\mathrm{GAG}$ concentration was still significantly higher than that of NCCM-P $(p<0.05)$.

After $28 \mathrm{~d}$, bovine CLC-containing alginate beads cultured in porcine NCCM (fractions) were analysed for DNA and GAG content and histology and compared with controls. Empty alginate beads did not bind GAGs (not shown). Although CLCs proliferated and formed clusters in all conditions, no statistically significant differences in DNA content were found between conditions (Fig. 2b). The GAG and GAG/DNA content was, however, significantly increased for culture in NCCM+ and NCCM-S compared to control medium $(p<0.05)$, whereas it was not increased for NCCM- or NCCM-P (Fig. 2c and 2d). The increased GAG content in NCCM+ and NCCM-S-treated beads was confirmed by Safranin O/Fast Green staining (Fig. 2e). Immunohistochemical staining showed no collagen type I deposition in any condition. Collagen type II, however, was deposited in all conditions: only in the pericellular region in the control- and NCCM-P-treated alginate beads, but more abundant after NCCM+, NCCM-S and NCCMtreatment.

\section{In vitro culture of canine CLCs in canine NCCM}

Canine NCCM and its fractions were analysed for their protein and GAG concentration (Fig. 3a). The protein and 
Table 3. Gene onthology analysis of proteins identified in porcine, canine and human NCCM.

\begin{tabular}{|c|c|c|c|c|c|c|}
\hline Rank & GO term & Name & $\begin{array}{c}\text { q-value FDR } \\
\text { B\&H }\end{array}$ & $\begin{array}{c}\text { Hit Count in } \\
\text { Query List }\end{array}$ & $\begin{array}{l}\text { Hit Count in } \\
\text { Genome }\end{array}$ & Hit in Query List \\
\hline 1 & GO:0005539 & $\begin{array}{l}\text { Glycosaminoglycan } \\
\text { binding }\end{array}$ & $7.96 \mathrm{E}-08$ & 11 & 216 & $\begin{array}{l}\text { THBS4, SERPINE2, ANG, FMOD, FN1, } \\
\text { COMP, ABI3BP, PRELP, ACAN, VCAN, } \\
\text { HAPLN1 }\end{array}$ \\
\hline 2 & GO:0005201 & $\begin{array}{l}\text { Extracellular matrix } \\
\text { structural constituent }\end{array}$ & $8.35 \mathrm{E}-07$ & 7 & 70 & $\begin{array}{l}\text { COL2A1, COL11A2, COMP, PRELP, ACAN, } \\
\text { LAMA4, LAMC1 }\end{array}$ \\
\hline 3 & GO:0005198 & $\begin{array}{l}\text { Structural molecule } \\
\text { activity }\end{array}$ & 4.30E-06 & 15 & 748 & $\begin{array}{l}\text { COL2A1, VIM, TUBB4B, KRT8, COL11A2, } \\
\text { KRT15, COMP, LMNA, KRT18, KRT19, } \\
\text { PRELP, ACAN, LAMA4, LAMB2, LAMC1 }\end{array}$ \\
\hline 4 & GO:0008201 & Heparin binding & $9.30 \mathrm{E}-06$ & 8 & 164 & $\begin{array}{l}\text { THBS4, SERPINE2, ANG, FMOD, FN1, } \\
\text { COMP, ABI3BP, PRELP }\end{array}$ \\
\hline 5 & GO:0005518 & Collagen binding & $1.23 \mathrm{E}-05$ & 6 & 71 & NID2, THBS4, FN1, COMP, ABI3BP, CSPG4 \\
\hline 6 & GO:0032403 & $\begin{array}{l}\text { Protein complex } \\
\text { binding }\end{array}$ & $1.48 \mathrm{E}-04$ & 15 & 1053 & $\begin{array}{l}\text { VIM, NID2, KRT8, THBS4, FN1, COMP, } \\
\text { ABI3BP, KRT19, CSPG4, PKM, LAMB2, } \\
\text { ACTN4, ACTN1, YWHAE, YWHAZ }\end{array}$ \\
\hline 7 & GO: 1901681 & $\begin{array}{l}\text { Sulphur compound } \\
\text { binding }\end{array}$ & $1.48 \mathrm{E}-04$ & 8 & 257 & $\begin{array}{l}\text { THBS4, SERPINE2, ANG, FMOD, FN1, } \\
\text { COMP, ABI3BP, PRELP }\end{array}$ \\
\hline 8 & GO:0019899 & Enzyme binding & $1.48 \mathrm{E}-04$ & 20 & 1851 & $\begin{array}{l}\text { A2M, VIM, HSPG2, FN1, COMP, LMNA, } \\
\text { CLU, PEBP1, ANXA2, VCAN, CSPG4, ALB, } \\
\text { LDHA, ENO1, YWHAE, YWHAG, YWHAZ, } \\
\text { PRDX6, EEF1A1, TPI1 }\end{array}$ \\
\hline 9 & GO:0004867 & $\begin{array}{l}\text { Serine-type } \\
\text { endopeptidase inhibitor } \\
\text { activity }\end{array}$ & 8.34E-04 & 5 & 96 & A2M, COL6A3, SERPINE2, PEBP1, CD109 \\
\hline 10 & GO:0097110 & Scaffold protein binding & $1.51 \mathrm{E}-03$ & 4 & 56 & VIM, KRT8, KRT15, KRT18 \\
\hline 11 & GO:0002020 & Protease binding & $1.63 \mathrm{E}-03$ & 5 & 115 & A2M, HSPG2, FN1, COMP, ANXA2 \\
\hline 12 & GO:0005178 & Integrin binding & $1.69 \mathrm{E}-03$ & 5 & 118 & THBS4, FN1, LAMB2, ACTN4, ACTN1 \\
\hline 13 & GO:0004857 & $\begin{array}{l}\text { Enzyme inhibitor } \\
\text { activity }\end{array}$ & $1.74 \mathrm{E}-03$ & 8 & 393 & $\begin{array}{l}\text { A2M, COL6A3, SERPINE2, PEBP1, ANXA2, } \\
\text { CD109, CHAD, YWHAG }\end{array}$ \\
\hline 14 & GO:0004634 & $\begin{array}{l}\text { Phosphopyruvate } \\
\text { hydratase activity }\end{array}$ & $1.74 \mathrm{E}-03$ & 2 & 4 & ENO1, ENO3 \\
\hline 15 & GO:0005540 & Hyaluronic acid binding & $1.79 \mathrm{E}-03$ & 3 & 24 & ACAN, VCAN, HAPLN1 \\
\hline 16 & GO:0019838 & Growth factor binding & $2.28 \mathrm{E}-03$ & 5 & 134 & COL2A1, A2M, COL6A1, HTRA1, CD109 \\
\hline 17 & GO:0003723 & RNA binding & $2.28 \mathrm{E}-03$ & 16 & 1608 & $\begin{array}{l}\text { VIM, TUBB4B, ANG, KRT18, PEBP1, } \\
\text { ANXA2, PRDX1, PKM, ACTN4, ACTN1, } \\
\text { ENO1, YWHAE, YWHAG, YWHAZ, } \\
\text { LGALS1, EEF1A1 }\end{array}$ \\
\hline 18 & GO:0061134 & $\begin{array}{l}\text { Peptidase regulator } \\
\text { activity }\end{array}$ & $2.39 \mathrm{E}-03$ & 6 & 221 & $\begin{array}{l}\text { A2M, COL6A3, SERPINE2, FN1, PEBP1, } \\
\text { CD109 }\end{array}$ \\
\hline 19 & GO:0016209 & Antioxidant activity & $2.51 \mathrm{E}-03$ & 4 & 75 & PRDX1, ALB, HBB, PRDX6 \\
\hline 20 & GO:0005509 & Calcium ion binding & $2.54 \mathrm{E}-03$ & 10 & 694 & $\begin{array}{l}\text { NID2, THBS4, EFEMP1, COMP, ANXA2, } \\
\text { MATN2, VCAN, ACTN4, ACTN1, EHD2 }\end{array}$ \\
\hline
\end{tabular}

Table 4. Pathway analysis of proteins identified in porcine and human NCCM.

\begin{tabular}{|c|c|l|c|c|c|l|}
\hline Rank & ID & \multicolumn{1}{|c|}{ Name } & $\begin{array}{c}\text { q-value } \\
\text { FDR B\&H }\end{array}$ & $\begin{array}{c}\text { Hit Count in } \\
\text { Query List }\end{array}$ & $\begin{array}{c}\text { Hit Count } \\
\text { in Genome }\end{array}$ & \multicolumn{1}{c|}{ Hit in Query List } \\
\hline 1 & 730306 & $\begin{array}{l}\text { Assembly of collagen } \\
\text { fibrils and other multimeric } \\
\text { structures }\end{array}$ & $5.9 \mathrm{E}-09$ & 7 & 54 & $\begin{array}{l}\text { COL3A1, COL5A1, COL5A2, COL6A2, COL11A1, } \\
\text { COL15A1, PCOLCE }\end{array}$ \\
\hline 2 & 645289 & $\begin{array}{l}\text { Collagen biosynthesis and } \\
\text { modifying enzymes }\end{array}$ & $1.1 \mathrm{E}-08$ & 7 & 65 & $\begin{array}{l}\text { COL3A1, COL5A1, COL5A2, COL6A2, COL11A1, } \\
\text { COL15A1, PCOLCE }\end{array}$ \\
\hline 3 & 645288 & Collagen formation & $3.5 \mathrm{E}-08$ & 7 & 87 & $\begin{array}{l}\text { COL3A1, COL5A1, COL5A2, COL6A2, COL11A1, } \\
\text { COL15A1, PCOLCE }\end{array}$ \\
\hline 4 & 576262 & $\begin{array}{l}\text { Extracellular matrix } \\
\text { organization }\end{array}$ & $1.9 \mathrm{E}-06$ & 8 & 264 & $\begin{array}{l}\text { COL3A1, COL5A1, COL5A2, COL6A2, COL11A1, } \\
\text { COL15A1, TNXB, PCOLCE }\end{array}$ \\
\hline 5 & 161004 & Recycling pathway of L1 & $4.5 \mathrm{E}-04$ & 3 & 27 & EZR, DPYSL2, MSN \\
\hline 6 & 106050 & Platelet degranulation & $5.6 \mathrm{E}-04$ & 4 & 85 & PFN1, PPIA, VCL, SOD1 \\
\hline 7 & 106048 & $\begin{array}{l}\text { Response to elevated platelet } \\
\text { cytosolic Ca2+ }\end{array}$ & $6.5 \mathrm{E}-04$ & 4 & 90 & PFN1, PPIA, VCL, SOD1 \\
\hline 8 & 105688 & Axon guidance & $3.0 \mathrm{E}-03$ & 5 & 262 & EZR, COL6A2, DPYSL2, PFN1, MSN \\
\hline 9 & 161003 & L1CAM interactions & $1.1 \mathrm{E}-02$ & 3 & 94 & EZR, DPYSL2, MSN \\
\hline 10 & 106034 & $\begin{array}{l}\text { Platelet activation, signalling } \\
\text { and aggregation }\end{array}$ & $1.1 \mathrm{E}-02$ & 4 & 214 & PFN1, PPIA, VCL, SOD1 \\
\hline
\end{tabular}


Table 5. Pathway analysis of proteins identified in canine and human NCCM.

\begin{tabular}{|c|c|c|c|c|c|c|}
\hline Rank & ID & Name & $\begin{array}{c}\text { q-value } \\
\text { FDR B\&H }\end{array}$ & $\begin{array}{c}\text { Hit Count in } \\
\text { Query List }\end{array}$ & $\begin{array}{l}\text { Hit Count } \\
\text { in Genome }\end{array}$ & Hit in Query List \\
\hline 1 & 106204 & Gluconeogenesis & $2.1 \mathrm{E}-07$ & \begin{tabular}{|l|}
6 \\
\end{tabular} & 33 & GPI,MDH1, ALDOA, GAPDH, ENO2, PGK1 \\
\hline 2 & 105911 & Glycolysis & $1.5 \mathrm{E}-06$ & 5 & 29 & GPI, ALDOA, GAPDH, ENO2, PGK1 \\
\hline 3 & 106196 & Metabolism of carbohydrates & $3.3 \mathrm{E}-06$ & 9 & 266 & $\begin{array}{l}\text { GPI, LUM, MDH1, DCN, ALDOA, GAPDH, } \\
\text { ENO2, PGK1, BGN }\end{array}$ \\
\hline 4 & 106199 & Glucose metabolism & $3.9 \mathrm{E}-06$ & 6 & 75 & GPI, MDH1, ALDOA, GAPDH, ENO2, PGK1 \\
\hline 5 & 833812 & ECM proteoglycans & $1.5 \mathrm{E}-05$ & 5 & 55 & SPARC, LUM, DCN, TNC, BGN \\
\hline 6 & 366238 & Amyloids & $1.0 \mathrm{E}-04$ & 5 & 85 & TGFBI, MFGE8, LYZ, HIST1H4A, GSN \\
\hline 7 & 576262 & $\begin{array}{l}\text { Extracellular matrix } \\
\text { organization }\end{array}$ & $2.1 \mathrm{E}-04$ & 7 & 264 & FBLN1, SPARC, LUM, DCN, TNC, BGN, DDR2 \\
\hline 8 & 771599 & $\begin{array}{l}\text { Binding and uptake of ligands } \\
\text { by scavenger receptors }\end{array}$ & $4.9 \mathrm{E}-04$ & 4 & 61 & SPARC, APOE, HBA1, HSP90AA1 \\
\hline 9 & 530764 & Disease & $3.1 \mathrm{E}-03$ & 11 & 1088 & $\begin{array}{l}\text { TGFBI, MFGE8, APOE, LUM, DCN, LYZ, } \\
\text { HIST1H4A, YWHAB, GSN, HSP90AA1, BGN }\end{array}$ \\
\hline 10 & 645310 & Dermatan sulphate biosynthesis & $6.0 \mathrm{E}-03$ & 2 & 11 & $\mathrm{DCN}, \mathrm{BGN}$ \\
\hline 11 & 105679 & $\begin{array}{l}\text { Caspase-mediated cleavage of } \\
\text { cytoskeletal proteins }\end{array}$ & 7.0E-03 & 2 & 12 & SPTAN1, GSN \\
\hline 12 & 645311 & CS/DS degradation & $8.9 \mathrm{E}-03$ & 2 & 14 & DCN, BGN \\
\hline 13 & 477135 & Metabolism & $1.5 \mathrm{E}-02$ & 12 & 1575 & $\begin{array}{l}\text { GPI, APOE, LUM, MDH1, HBA1, DCN, ALDOA, } \\
\text { GAPDH, ENO2, PGK1, HSP90AA1, BGN }\end{array}$ \\
\hline 14 & 645309 & $\begin{array}{l}\text { Chondroitin sulphate } \\
\text { biosynthesis }\end{array}$ & $1.8 \mathrm{E}-02$ & 2 & 21 & DCN, BGN \\
\hline 15 & 106050 & Platelet degranulation & $2.0 \mathrm{E}-02$ & 3 & 85 & SERPINA1, SPARC, ALDOA \\
\hline 16 & 106048 & $\begin{array}{l}\text { Response to elevated platelet } \\
\text { cytosolic } \mathrm{Ca} 2+\end{array}$ & $2.3 \mathrm{E}-02$ & 3 & 90 & SERPINA1, SPARC, ALDOA \\
\hline 17 & 645305 & $\begin{array}{l}\text { A tetrasaccharide linker } \\
\text { sequence is required for GAG } \\
\text { synthesis }\end{array}$ & $2.5 \mathrm{E}-02$ & 2 & 26 & DCN, BGN \\
\hline 18 & 685546 & MPS VII - Sly syndrome & 3.7E-02 & 3 & 121 & LUM, DCN, BGN \\
\hline 19 & 685536 & Mucopolysaccharidoses & $3.7 \mathrm{E}-02$ & 3 & 121 & LUM, DCN, BGN \\
\hline 20 & 685547 & MPS IX - Natowicz syndrome & 3.7E-02 & 3 & 121 & LUM, DCN, BGN \\
\hline
\end{tabular}

Table 6. Pathway analysis of proteins identified in porcine and canine NCCM.

\begin{tabular}{|c|c|l|c|c|c|c|}
\hline Rank & ID & \multicolumn{1}{|c|}{ Name } & $\begin{array}{c}\text { q-value } \\
\text { FDR } \\
\text { B\&H }\end{array}$ & $\begin{array}{c}\text { Hit Count } \\
\text { in Query } \\
\text { List }\end{array}$ & $\begin{array}{c}\text { Hit Count } \\
\text { in } \\
\text { Genome }\end{array}$ & Hit in Query List \\
\hline 1 & 106248 & Post-chaperonin tubulin folding pathway & $2.88 \mathrm{E}-02$ & 2 & 19 & TUBB2A, TUBB2B \\
\hline 2 & 106245 & Formation of tubulin folding intermediates by CCT/TriC & $2.88 \mathrm{E}-02$ & 2 & 22 & TUBB2A, TUBB2B \\
\hline 3 & 106244 & Prefoldin mediated transfer of substrate to CCT/TriC & $2.88 \mathrm{E}-02$ & 2 & 28 & TUBB2A, TUBB2B \\
\hline 4 & 106243 & Cooperation of prefoldin and TriC/CCT in actin and tubulin folding & $2.88 \mathrm{E}-02$ & 2 & 29 & TUBB2A, TUBB2B \\
\hline 5 & 106262 & Striated muscle contraction & $2.88 \mathrm{E}-02$ & 2 & 31 & TPM1, ACTN2 \\
\hline 6 & 106242 & Chaperonin-mediated protein folding & $4.66 \mathrm{E}-02$ & 2 & 50 & TUBB2A, TUBB2B \\
\hline 7 & 106261 & Muscle contraction & $4.66 \mathrm{E}-02$ & 2 & 51 & TPM1, ACTN2 \\
\hline 8 & 106241 & Protein folding & $4.66 \mathrm{E}-02$ & 2 & 55 & TUBB2A, TUBB2B \\
\hline
\end{tabular}

Table 7. Pathway analysis of proteins identified only in porcine NCCM.

\begin{tabular}{|c|c|l|c|c|c|l|}
\hline Rank & ID & \multicolumn{1}{c|}{ Name } & $\begin{array}{c}\text { q-value } \\
\text { FDR B\&H }\end{array}$ & $\begin{array}{c}\text { Hit Count in } \\
\text { Query List }\end{array}$ & $\begin{array}{c}\text { Hit Count in } \\
\text { Genome }\end{array}$ & \multicolumn{1}{c|}{ Hit in Query List } \\
\hline 1 & 106412 & Activation of C3 and C5 & 0.00829 & 2 & 5 & C4A, CFB \\
\hline 2 & 576254 & Regulation of complement cascade & 0.04694 & 2 & 22 & C4A, CFB \\
\hline
\end{tabular}

Table 8. Pathway analysis of proteins identified only in canine NCCM.

\begin{tabular}{|c|c|l|c|c|c|l|}
\hline Rank & ID & \multicolumn{1}{|c|}{ Name } & $\begin{array}{c}\text { q-value } \\
\text { FDR B\&H }\end{array}$ & $\begin{array}{c}\text { Hit Count in } \\
\text { Query List }\end{array}$ & $\begin{array}{c}\text { Hit Count in } \\
\text { Genome }\end{array}$ & \multicolumn{1}{|c|}{ Hit in Query List } \\
\hline 1 & 576262 & Extracellular matrix organization & 0.02383 & 6 & 264 & $\begin{array}{l}\text { MFAP4, COL11A2, EFEMP2, } \\
\text { NCAM1, LOXL3, CDH1 }\end{array}$ \\
\hline 2 & 730310 & Elastic fibre formation & 0.02651 & 3 & 41 & MFAP4, EFEMP2, LOXL3 \\
\hline 3 & 106248 & Post-chaperonin tubulin folding pathway & 0.04144 & 2 & 19 & TUBB4A, TUBA1A \\
\hline 4 & 105688 & Axon guidance & 0.04144 & 5 & 262 & $\begin{array}{l}\text { CFL1, SLIT3, NCAM1, SDCBP, } \\
\text { SEMA3E }\end{array}$ \\
\hline 5 & 106245 & $\begin{array}{l}\text { Formation of tubulin folding intermediates by } \\
\text { CCT/TriC }\end{array}$ & 0.04565 & 2 & 22 & TUBB4A, TUBA1A \\
\hline
\end{tabular}


Table 9. Pathway analysis of proteins identified only in human NCCM.

\begin{tabular}{|c|c|c|c|c|c|c|}
\hline Rank & ID & Name & $\begin{array}{c}\text { q-value } \\
\text { FDR B\&H }\end{array}$ & $\begin{array}{c}\text { Hit Count } \\
\text { in Query } \\
\text { List }\end{array}$ & $\begin{array}{c}\text { Hit } \\
\text { Count in } \\
\text { Genome }\end{array}$ & Hit in Query List \\
\hline 1 & 106406 & $\begin{array}{l}\text { Initial triggering of } \\
\text { complement }\end{array}$ & 4.93E-09 & 9 & 40 & $\begin{array}{l}\text { CFD, IGHG1, IGHG2, IGHG3, IGHG4, IGKC, C1R, } \\
\text { C1S, C3 }\end{array}$ \\
\hline 2 & 576262 & $\begin{array}{l}\text { Extracellular matrix } \\
\text { organization }\end{array}$ & $2.82 \mathrm{E}-08$ & 16 & 264 & $\begin{array}{l}\text { THBS1, COL9A1, COL12A1, FBLN2, FBN1, } \\
\text { COL16A1, P4HB, LOXL2, MATN3, FGA, COL14A1, } \\
\text { MATN4, MMP3, PPIB, COL1A1, COL1A2 }\end{array}$ \\
\hline 3 & 106405 & Complement cascade & $6.88 \mathrm{E}-08$ & 9 & 58 & $\begin{array}{l}\text { CFD, IGHG1, IGHG2, IGHG3, IGHG4, IGKC, C1R, } \\
\text { C1S, C3 }\end{array}$ \\
\hline 4 & 645288 & Collagen formation & $1.23 \mathrm{E}-07$ & 10 & 87 & $\begin{array}{l}\text { COL9A1, COL12A1, COL16A1, P4HB, LOXL2, } \\
\text { COL14A1, MMP3, PPIB, COL1A1, COL1A2 }\end{array}$ \\
\hline 5 & 106409 & $\begin{array}{l}\text { Classical antibody-mediated } \\
\text { complement activation }\end{array}$ & $1.35 \mathrm{E}-07$ & 7 & 28 & IGHG1, IGHG2, IGHG3, IGHG4, IGKC, C1R, C1S \\
\hline 6 & 106407 & $\begin{array}{l}\text { Creation of } \mathrm{C} 4 \text { and } \mathrm{C} 2 \\
\text { activators }\end{array}$ & 5.19E-07 & 7 & 34 & IGHG1, IGHG2, IGHG3, IGHG4, IGKC, C1R, C1S \\
\hline 7 & 645289 & $\begin{array}{l}\text { Collagen biosynthesis and } \\
\text { modifying enzymes }\end{array}$ & $2.26 \mathrm{E}-06$ & 8 & 65 & $\begin{array}{l}\text { COL9A1, COL12A1, COL16A1, P4HB, COL14A1, } \\
\text { PPIB, COL1A1, COL1A2 }\end{array}$ \\
\hline 8 & 106050 & Platelet degranulation & $1.86 \mathrm{E}-04$ & 7 & 85 & $\begin{array}{l}\text { CFD, FLNA, THBS1, CALM2, CALU, FGA, } \\
\text { TMSB4X }\end{array}$ \\
\hline 9 & 106048 & $\begin{array}{l}\text { Response to elevated platelet } \\
\text { cytosolic } \mathrm{Ca} 2+\end{array}$ & $2.35 \mathrm{E}-04$ & 7 & 90 & $\begin{array}{l}\text { CFD, FLNA, THBS1, CALM2, CALU, FGA, } \\
\text { TMSB4X }\end{array}$ \\
\hline 10 & 771578 & FCGR activation & $2.35 \mathrm{E}-04$ & 5 & 34 & IGHG1, IGHG2, IGHG3, IGHG4, IGKC \\
\hline 11 & 771599 & $\begin{array}{l}\text { Binding and uptake of ligands } \\
\text { by scavenger receptors }\end{array}$ & $2.70 \mathrm{E}-04$ & 6 & 61 & HSP90B1, IGKC, LRP1, HBD, COL1A1, COL1A2 \\
\hline 12 & 730309 & Collagen degradation & $3.54 \mathrm{E}-04$ & 5 & 38 & COL9A1, COL12A1, COL16A1, COL14A1, MMP3 \\
\hline 13 & 771580 & $\begin{array}{l}\text { Role of phospholipids in } \\
\text { phagocytosis }\end{array}$ & $8.80 \mathrm{E}-04$ & 5 & 46 & IGHG1, IGHG2, IGHG3, IGHG4, IGKC \\
\hline 14 & 771579 & $\begin{array}{l}\text { Regulation of actin dynamics } \\
\text { for phagocytic cup formation }\end{array}$ & $1.16 \mathrm{E}-03$ & 6 & 81 & IGHG1, IGHG2, IGHG3, IGHG4, IGKC, HSP90AB1 \\
\hline 15 & 106110 & $\begin{array}{l}\text { Integrin cell surface } \\
\text { interactions }\end{array}$ & $4.22 \mathrm{E}-03$ & 5 & 66 & THBS1, COL9A1, FBN1, COL16A1, FGA \\
\hline 16 & 771577 & $\begin{array}{l}\text { Fcgamma receptor (FCGR) } \\
\text { dependent phagocytosis }\end{array}$ & $4.22 \mathrm{E}-03$ & 6 & 105 & IGHG1, IGHG2, IGHG3, IGHG4, IGKC, HSP90AB1 \\
\hline 17 & 106410 & $\begin{array}{l}\text { Alternative complement } \\
\text { activation }\end{array}$ & $9.39 \mathrm{E}-03$ & 2 & 4 & CFD, C3 \\
\hline 18 & 833814 & $\begin{array}{l}\text { Scavenging by class A } \\
\text { receptors }\end{array}$ & $1.01 \mathrm{E}-02$ & 3 & 19 & HSP90B1, COL1A1, COL1A2 \\
\hline 19 & 576263 & $\begin{array}{l}\text { Degradation of the extracellular } \\
\text { matrix }\end{array}$ & $1.42 \mathrm{E}-02$ & 5 & 89 & COL9A1, COL12A1, COL16A1, COL14A1, MMP3 \\
\hline 20 & 730306 & $\begin{array}{l}\text { Assembly of collagen fibrils } \\
\text { and other multimeric structures }\end{array}$ & $1.74 \mathrm{E}-02$ & 4 & 54 & LOXL2, MMP3, COL1A1, COL1A2 \\
\hline
\end{tabular}

Table 10. Proteins associated with transcription factor binding sites in porcine, canine and human NCCM.

\begin{tabular}{|c|c|c|c|c|c|}
\hline $\begin{array}{l}\text { Venn- } \\
\text { group }\end{array}$ & ID & $\begin{array}{l}\text { q-value } \\
\text { FDR } \\
\text { B\&H }\end{array}$ & $\begin{array}{c}\text { Hit Count } \\
\text { in Query } \\
\text { List }\end{array}$ & \begin{tabular}{c|} 
Hit \\
Count in \\
Genome \\
\end{tabular} & Hit in Query List \\
\hline Common & TGANTCA_V\$AP1_C & $1.63 \mathrm{E}-02$ & 15 & 919 & $\begin{array}{l}\text { XYLT1, HSPG2, KRT8, KRT15, KRT19, CSPG4, PKM, LAMC1, } \\
\text { ACTN4, ENO1, ENO3, YWHAG, YWHAZ, LGALS1, EEF1A1 }\end{array}$ \\
\hline Common & GGGTGGRR_V\$PAX4_03 & 4.51E-02 & 15 & 1068 & $\begin{array}{l}\text { A2M, VIM, HSPG2, NID2, COL6A3, COL11A2, RARRES2, } \\
\text { PRELP, CD109, LAMB2, YWHAE, YWHAG, YWHAZ, EEF1A1, } \\
\text { HAPLN1 }\end{array}$ \\
\hline $\begin{array}{l}\text { Canine } \\
\text { and } \\
\text { porcine }\end{array}$ & TATAAA_V\$TATA_01 & 2.49E-02 & 7 & 1075 & CP,LECT2, SEMA3C, ENPP2, KRT14, ACTN2, SMOC1 \\
\hline Canine & V\$ZIC3_01 & $3.55 \mathrm{E}-02$ & 6 & 213 & CRYAB, TIMP3, EFEMP2, SLIT3, LOXI3, CHST3 \\
\hline Canine & GGGAGGRR_V\$MAZ_Q6 & $3.55 \mathrm{E}-02$ & 17 & 1838 & $\begin{array}{l}\text { TUBB4A, KRT13, COL11A2, KRT17, MRC2, CFL1, LECT1, } \\
\text { EFEMP2, SLIT3, CHST6, NCAM1, PTRF, LOXL3, CDH2, } \\
\text { LDHB, SLC2A1, SOD3 }\end{array}$ \\
\hline
\end{tabular}



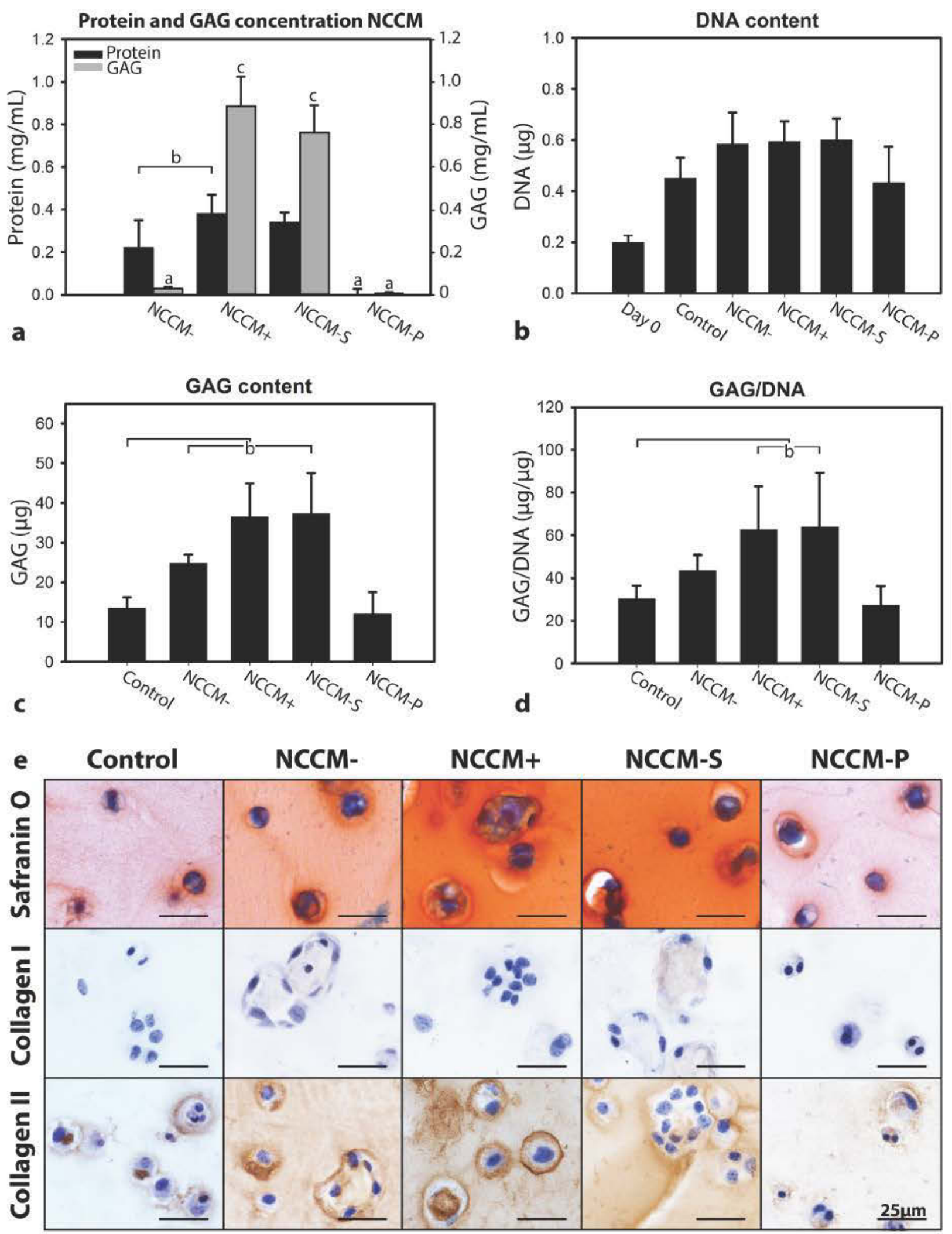

Fig. 2. Soluble factors derived from porcine NC-conditioned medium (NCCM) exert anabolic effects on bovine chondrocyte-like cells (CLCs) derived from caudal intervertebral discs (IVDs). Cell proliferation and matrix production of bovine CLCs cultured in alginate beads in basal culture medium (control), NCCM from dedifferentiated NCs (NCCM-), NCCM from healthy NCs (NCCM + ), and the soluble (NCCM-S) and pelletable (NCCM-P) fraction of NCCM + , which were separated by ultracentrifugation. (a) Protein (black) and glycosaminoglycan (GAG, grey) concentration (mean $\pm \mathrm{SD}$ ) of porcine NCCM (fractions). (b-d) DNA, GAG and GAG/DNA content (mean $\pm \mathrm{SD}$ ) of bovine CLC alginate beads at day 28. (e) Safranin O/Fast Green staining and collagen type I and II immunohistochemistry of bovine CLC alginate beads at day 28. a, significant difference between this condition and all other conditions $(p<0.05)$; b, significant difference between these conditions $(p<0.05)$; $\mathrm{c}$, significant difference between this condition and all other conditions except for the other condition indicated with 'c' $(p<0.05) ; n=4$. 
Protein and GAG concentration NCCM

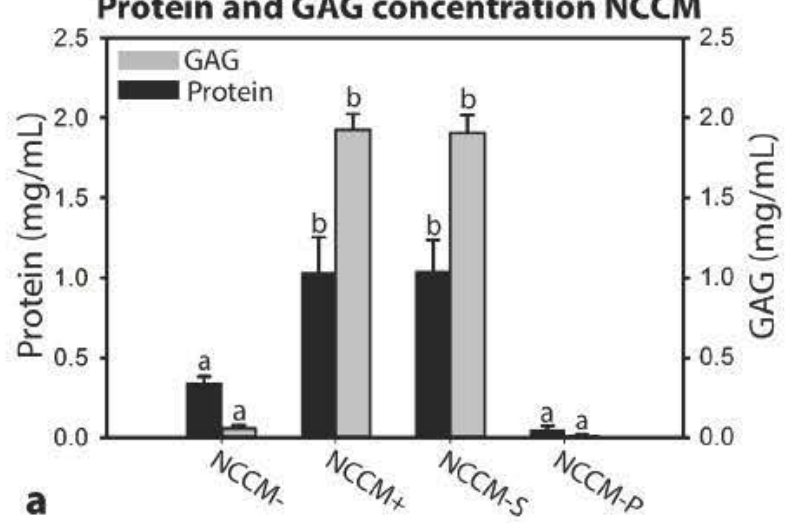

a

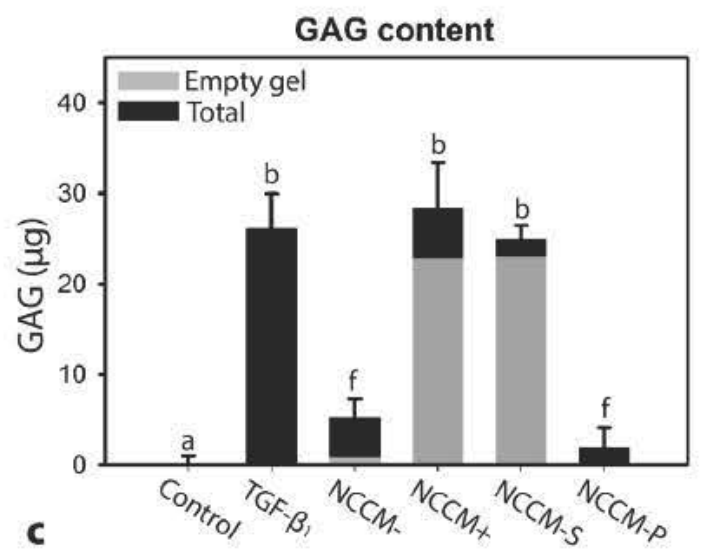

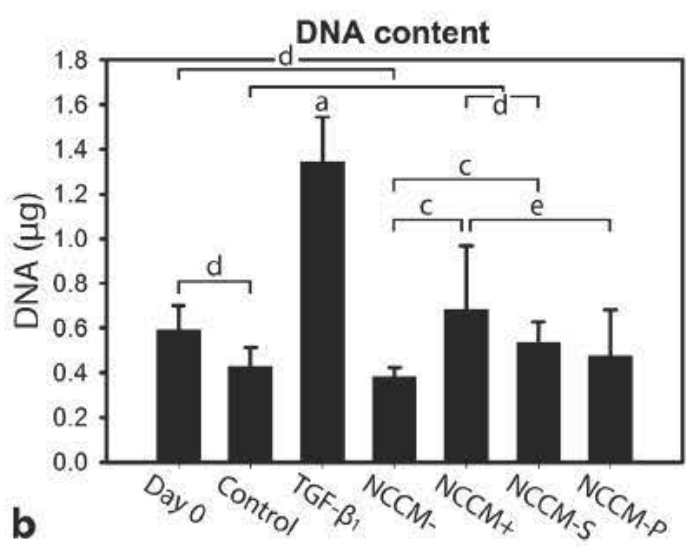

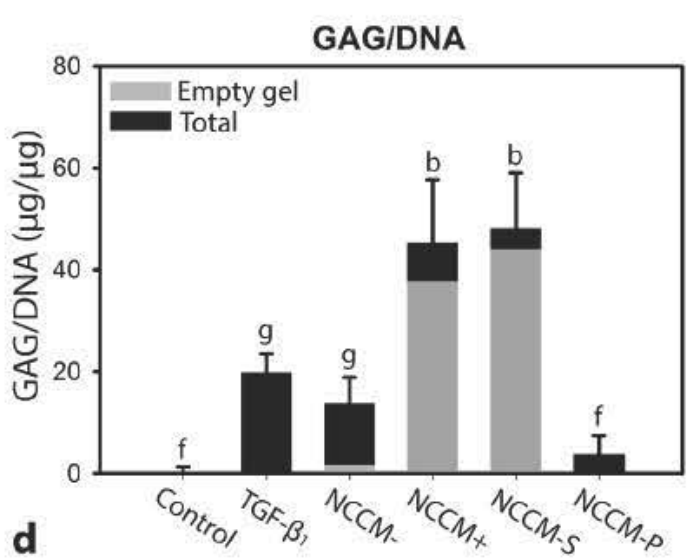

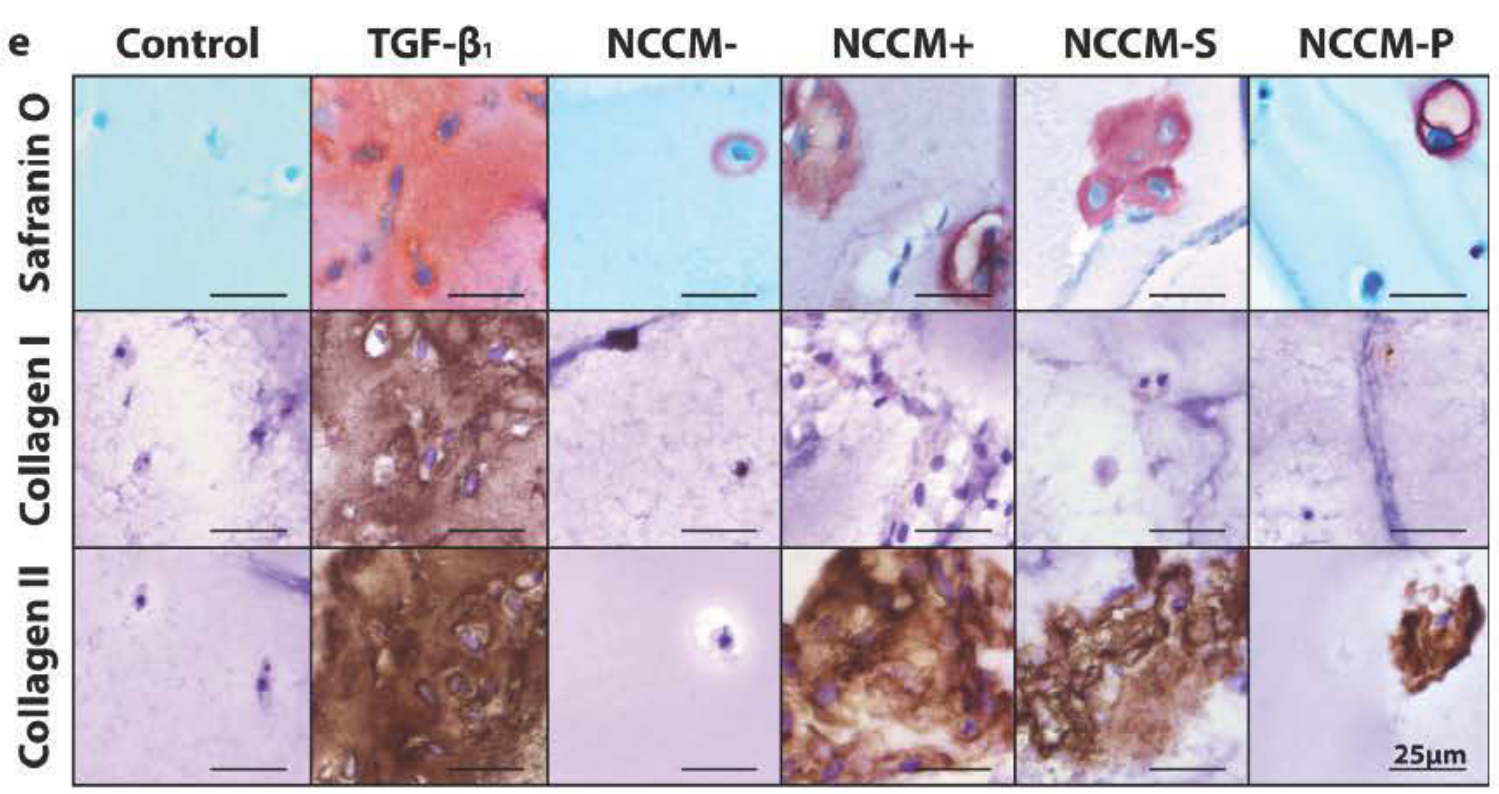

Fig. 3. Both soluble and pelletable factors derived from canine NC-conditioned medium (NCCM) exert anabolic effects on canine chondrocyte-like cells (CLCs) derived from degenerated intervertebral discs (IVDs). Cell proliferation and matrix production of canine CLCs cultured in hydrogels in basal culture medium (control), basal culture medium supplemented with $10 \mathrm{ng} / \mathrm{mL}$ TGF- $\beta_{1}$, NCCM from dedifferentiated NCs (NCCM-), NCCM from healthy NCs (NCCM + ), and the soluble (NCCM-S) and pelletable (NCCM-P) fraction of NCCM+, which were separated by ultracentrifugation. (a) Protein (black) and glycosaminoglycan (GAG, grey) concentration (mean $\pm \mathrm{SD}$ ) of canine NCCM (fractions). (b-d) DNA, GAG and GAG/DNA content (mean \pm SD) of canine CLC hydrogels at day 28 . The grey colour in the black bars indicates the level of GAGs present in cell-free NCCM-treated hydrogels for these conditions. (e) Safranin O/Fast Green staining and collagen type I and II immunohistochemistry of canine CLC hydrogels at day 28 . Significant differences are indicated for non-corrected data (not corrected for empty gels). a, significant difference between this condition and all other conditions $(p<0.001)$; b, significant difference between this condition and all other conditions except for the other condition indicated with ' $\mathrm{b}$ ' $(p<0.001)$; $\mathrm{c}, \mathrm{d}$ and $\mathrm{e}$, significant difference between these conditions with $p<0.001$, $p<0.01$ and $p<0.05$, respectively; $\mathrm{f}$ and $\mathrm{g}$, significant difference between this condition and all other conditions with $p<0.01$ and $p<0.05$, respectively; $n=8$ for DNA and GAG content and $n=4-8$ for histology. 

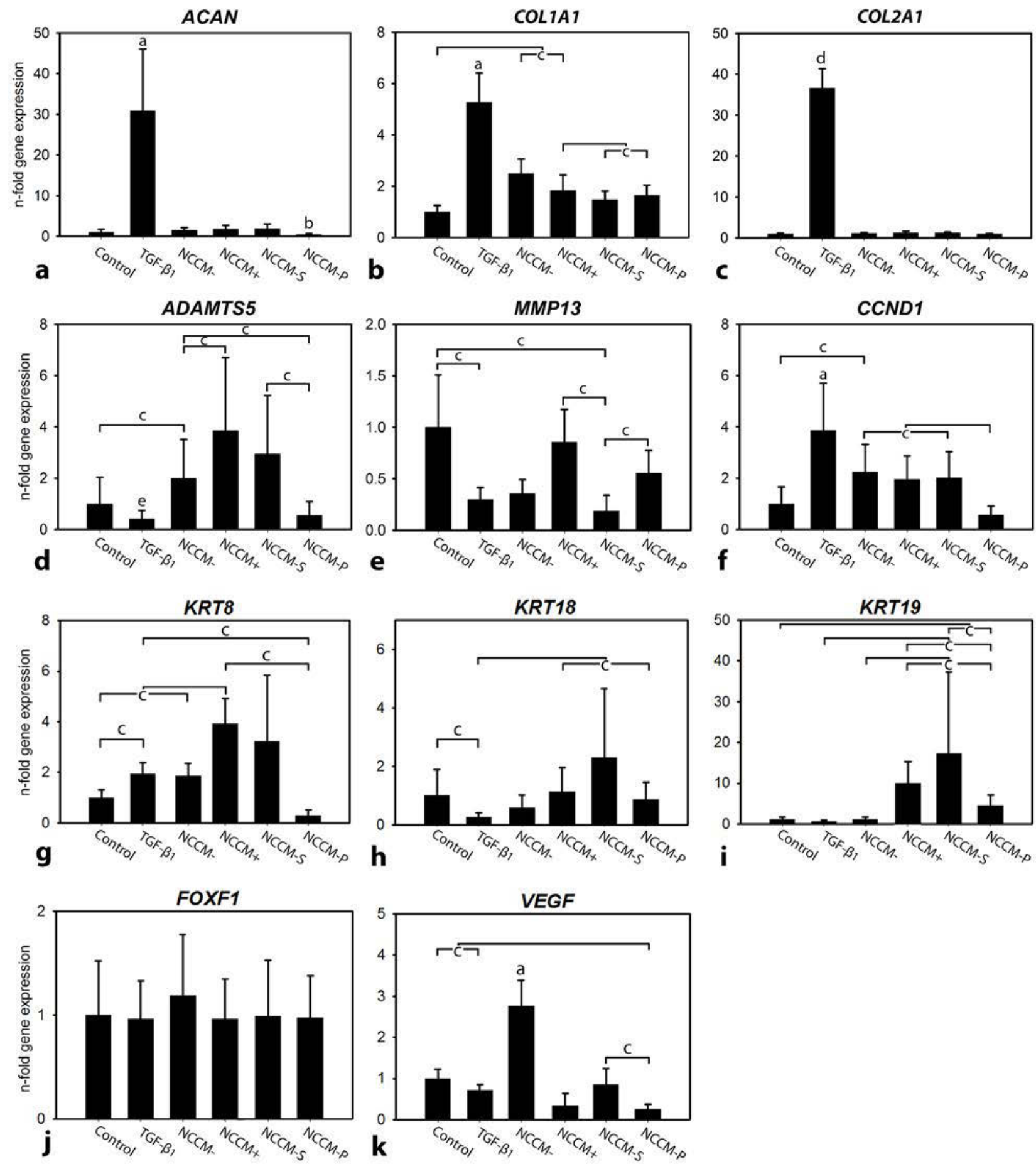

Fig. 4. Only the soluble factors present in canine NC-conditioned medium (NCCM) stimulate expression of genes related to cell proliferation of canine chondrocyte-like cell (CLC), but none of the NCCM (fractions) effects expression of genes related to matrix production. Target gene expression levels of canine CLCs cultured in hydrogels in basal culture medium (control), basal culture medium supplemented with $10 \mathrm{ng} / \mathrm{mL}$ TGF- $\beta_{1}$, NCCM from dedifferentiated $\mathrm{NCs}(\mathrm{NCCM}-)$, NCCM from healthy NCs (NCCM+), and the soluble (NCCM-S) and pelletable (NCCM-P) fraction of $\mathrm{NCCM}+$, which were separated by ultracentrifugation. (a-k) Relative ACAN, COL1A1, COL2A1, ADAMTS5, MMP13, CCND1, KRT8, KRT18, KRT19, FOXF1, and VEGF gene expression (mean \pm SD) of the hydrogels at day 4 . The control hydrogels were set at 1 . a, significant difference between this condition and all other conditions $(p<0.05)$; b, significant difference between this condition and all other conditions except control $(p<0.05)$; c, significant difference between these conditions ( $p<0.05)$; d, significant difference between this condition and all other conditions $(p<0.01)$; e, significant difference between this condition and all other conditions except NCCM-P $(p<0.05) ; n=8$. 

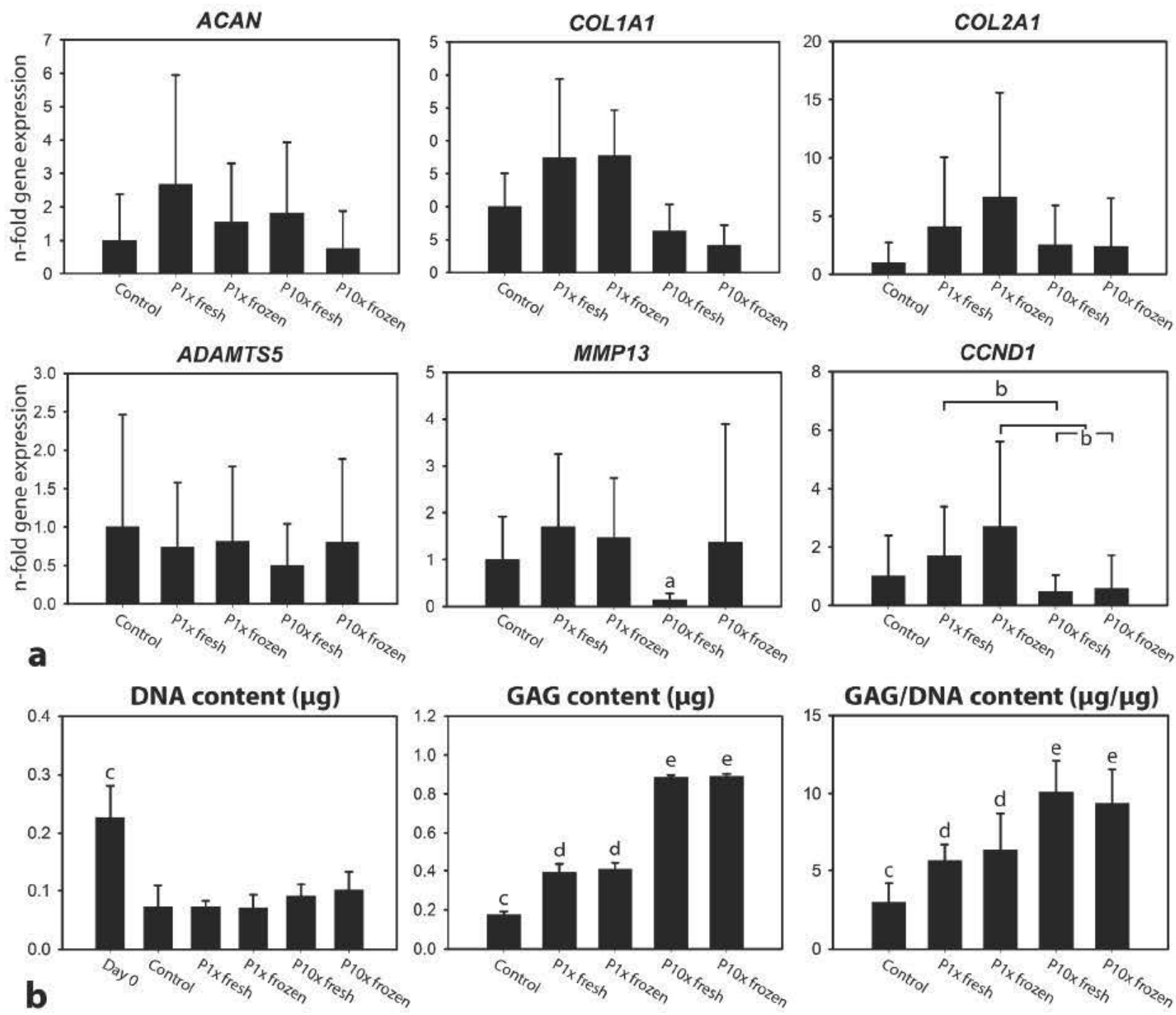

Fig. 5. Frozen canine pelletable NCCM factors exert comparable anabolic effects as freshly applied (non-frozen) pelletable NCCM factors, while a ten times higher concentration of pelletable factors induces a more pronounced effect on canine chondrocyte-like cell (CLC) matrix production. Target gene expression levels and DNA and glycosaminoglycan (GAG) content of canine CLCs cultured in micro-aggregates in basal culture medium (control), or $1 \times$ concentrated freshly generated, non-frozen NCCM-P $(\mathrm{P} 1 \times$ fresh $), 1 \times$ concentrated NCCM-P frozen at $-70{ }^{\circ} \mathrm{C}$ (P1 $\times$ frozen), $10 \times$ concentrated freshly generated, non-frozen NCCM-P $(\mathrm{P} 10 \times$ fresh) and $10 \times$ concentrated frozen NCCM-P (P10× frozen). (a) Relative $A C A N, C O L 1 A 1, C O L 2 A 1, A D A M T S 5, M M P 13$ and $C C N D 1$ gene expression (mean $\pm \mathrm{SD}$ ) of the micro-aggregates at day 4. The control micro-aggregates were set at 1. (b) DNA, GAG and GAG/DNA content (mean \pm SD) of the canine CLC micro-aggregates at day 7. a, significant difference between this condition and all other conditions $(p<0.05)$; b, significant difference between these conditions $(p<0.05)$; $\mathrm{c}$, significant difference between this condition and all other conditions $(p<0.01)$; d, significant difference between this condition and all other conditions except for the other condition indicated with ' $\mathrm{d}$ ' $(p<0.01)$; e, significant difference between this condition and all other conditions except for the other condition indicated with ' $\mathrm{e}$ ' $(p<0.01) ; n=8$.

Table 11. Proteins associated with miRNAs in porcine and human NCCM.

\begin{tabular}{|l|c|c|c|c|l|}
\hline & ID & $\begin{array}{c}\text { q-value } \\
\text { FDR B\&H }\end{array}$ & $\begin{array}{c}\text { Hit Count in } \\
\text { Query List }\end{array}$ & $\begin{array}{c}\text { Hit Count } \\
\text { in Genome }\end{array}$ & \multicolumn{1}{c|}{ Hit in Query List } \\
\hline $\begin{array}{l}\text { Porcine and } \\
\text { human }\end{array}$ & hsa-miR-29b & $2.48 \mathrm{E}-02$ & 7 & 850 & COL3A1, COL5A1, COL5A2, DPYSL2, COL11A1, COL15A1, VCL \\
\hline $\begin{array}{l}\text { Porcine and } \\
\text { human }\end{array}$ & hsa-miR-29a & $2.48 \mathrm{E}-02$ & 7 & 850 & COL3A1, COL5A1, COL5A2, DPYSL2, COL11A1, COL15A1, VCL \\
\hline $\begin{array}{l}\text { Porcine and } \\
\text { human }\end{array}$ & hsa-miR-29c & $2.48 \mathrm{E}-02$ & 7 & 850 & COL3A1, COL5A1, COL5A2, DPYSL2, COL11A1, COL15A1, VCL \\
\hline $\begin{array}{l}\text { Human } \\
\text { only }\end{array}$ & hsa-miR-29c & $2.24 \mathrm{E}-02$ & 4 & 31 & FBN1, FGA, COL1A1, COL1A2 \\
\hline
\end{tabular}


GAG concentration of canine NCCM + and NCCM-S was significantly higher than that of NCCM- and NCCM-P, whereas the protein and GAG concentration of NCCM-P was significantly lower than that of NCCM- $(p<0.001$, Fig. 3a).

After $4 \mathrm{~d}$ of culture, gene expression profiling was performed on the canine CLC-containing hydrogels and after $28 \mathrm{~d}$ of culture, the hydrogels were analysed for DNA and GAG content and histology. The DNA content and CCND1 (a marker for cell proliferation) expression of the TGF- $\beta_{1}$-treated hydrogels was significantly increased compared with all other conditions $(p<0.05$, Figs. $3 \mathbf{b}$ and 4f). Furthermore, NCCM+ and NCCM-S-treated hydrogels showed a significantly increased DNA content compared with controls, and NCCM + treatment showed a significantly increased DNA content compared with NCCM-P and NCCM- treatment ( $p<0.05$, Fig. 3b). CCND1 expression was significantly lower in NCCM-Ptreated CLCs than in NCCM-/NCCM+/NCCM-S-treated CLCs $(p<0.05$, Fig. $4 \mathbf{f})$.

Using the DMMB assay, empty (no cell-containing) hydrogels were found to incorporate a large amount of NCCM-derived GAGs, indicated by the grey bars in Fig. 3c. The GAG content of the control hydrogels was significantly lower than that of all other conditions $\left(p<0.001\right.$, Fig. 3c). TGF- $\beta_{1}$, NCCM + and NCCM-S treatment induced the highest total GAG content of the CLC-containing hydrogels: significantly higher than after NCCM - and NCCM-P treatment ( $p<0.001$, Fig. 3c). The GAG content of the NCCM-P-treated hydrogels was significantly lower than that of the hydrogels treated with NCCM- $(p<0.01$, Fig.3c). The total GAG/DNA content of $\mathrm{NCCM}+$ and NCCM-S-treated hydrogels was the highest, followed by hydrogels treated with TGF- $\beta_{1}$, NCCM-, NCCM-P and basal culture medium, respectively $(p<0.05$, Fig. 3d). Safranin O/Fast Green staining indicated that most GAGs were deposited in the TGF- $\beta_{1}$-treated hydrogels, followed by NCCM+ and NCCM-S-treated hydrogels (Fig. 3e). Collagen type I deposition was only induced by TGF- $\beta_{1}$ treatment, not by NCCM fractions (Fig. $3 \mathbf{e})$. Collagen type II was mostly deposited in $\mathrm{NCCM}+$, NCCM-S, and TGF- $\beta_{1}$-treated hydrogels, but also some collagen type II was present in NCCM-P-treated hydrogels (Fig. 3e). Affirmatively, at the gene expression level, TGF- $\beta_{1}$ treatment significantly induced ACAN, COL1A1 and COL2A1 mRNA compared with all other conditions $(p<0.05$, Fig. 4a-c). In contrast, NCCM (fractions) did not influence $C O L 2 A 1$ expression compared with controls (Fig. 4a-c). NCCM-P inhibited ACAN expression and NCCMand $\mathrm{NCCM}+$ induced COL1A1 expression compared with controls $(p<0.05$, Fig. 4a-c). COL10A1 expression was not detected in any condition (data not shown).

Furthermore, TGF- $\beta_{1}$ treatment significantly reduced ADAMTS5 expression compared with all other conditions, whereas NCCM- significantly induced ADAMTS5 expression compared with controls and NCCM-P ( $p<0.05$, Fig. 4d). NCCM+ induced even more ADAMTS5 expression than NCCM- and NCCM-S increased ADAMTS5 expression compared with NCCM-P $(p<0.05$, Fig. 4d). MMP13 expression was significantly decreased by TGF- $\beta_{1}$ treatment compared with controls, whereas
NCCM-S reduced MMP13 expression compared with controls, NCCM+ and NCCM-P ( $p<0.05$, Fig. 4e). Expression of the notochordal marker $T$ was not detected regardless of the culture condition (data not shown), whereas expression of notochordal marker KRT8 was significantly higher in micro-aggregates treated with $\mathrm{NCCM}+$ than in micro-aggregates treated with NCCM-P, NCCM-, TGF- $\beta_{1}$ and the negative controls $(p<0.05$, Fig. $4 \mathbf{g}$ ). Expression of NP marker KRT18 was significantly increased in micro-aggregates treated with basal culture medium, NCCM+, NCCM-S and NCCM-P compared with TGF- $\beta_{1}$-treated micro-aggregates ( $p<0.05$, Fig. $\left.4 \mathbf{h}\right)$. KRT19 expression was significantly increased by NCCM-P and NCCM-S treatment compared with controls $(p<0.05$, Fig. 4i). Additionally, NCCM+, NCCM-S and NCCM-P treatment significantly increased the expression of this NP marker compared with NCCM- and TGF- $\beta_{1}$ treatment $(p<0.05$, Fig. $4 \mathbf{i})$. In contrast, FOXF1 expression was not influenced by the culture conditions (Fig. 4j). Expression of the angiogenic marker VEGF was significantly higher in micro-aggregates treated with $\mathrm{NCCM}-$ than in all other conditions ( $p<0.05$, Fig. 4 j). Furthermore, VEGF expression was significantly decreased by NCCM-P treatment compared with control, TGF- $\beta_{1}$ and NCCM-S treatment $(p<0.05)$. Apoptosis-related genes $(B A X, B C L 2$, $C A S P 3)$ were not differentially expressed between the conditions (data not shown).

\section{Fresh versus frozen pelletable factors present in canine NCCM}

Gene expression profiling of CD canine CLC microaggregates cultured in basal culture medium (control), $1 \times$ concentrated fresh (non-frozen) and frozen NCCM-P and $10 \times$ concentrated fresh (non-frozen) and frozen NCCM-P was performed at day 4. Due to donor variability, high standard deviations were obtained (Fig. 5a). At day 7, the DNA content of all micro-aggregates was significantly decreased compared with day $0(p<0.01$, Fig 5b). The GAG and GAG/DNA content of the controls was significantly lower than that of the micro-aggregates treated with $1 \times$ and $10 \times$ concentrated NCCM-P $(p<0.01$, Fig $5 \mathbf{b})$. Moreover, the GAG and GAG/DNA content of the micro-aggregates treated with $10 \times$ concentrated NCCM-P was significantly higher than that of the micro-aggregates treated with $1 \times$ concentrated NCCM-P $(p<0.01$, Fig $5 \mathbf{b})$, indicating a concentration-dependent effect, which could be repeated with frozen NCCM-P. This indicates that freezing the pelletable factors for a short period $(1 \mathrm{~h}-4 \mathrm{~d})$ at $-70{ }^{\circ} \mathrm{C}$ in EV-depleted PBS/0.2\% BSA did not affect their biological effect.

\section{Discussion}

NCCM exerts cross-species anabolic effects on CLCs Porcine, canine and human NC-secreted factors have already shown potential for IVD regeneration (Abbott et al., 2012; Bach et al., 2015; de Vries et al., 2016; Gantenbein et al., 2014; Korecki et al., 2010; Purmessur et al., 2011). With a clinical directive in mind, the aim of this study was to delineate underlying bioactive $\mathrm{NC}$-secreted substances 
(with the focus on proteins and EVs) resulting in IVD regeneration. The present study shows that porcine and canine $\mathrm{NCCM}+$ have the potential to exert a regenerative effect on bovine and canine CLCs, respectively. Secreted factors from healthy $\mathrm{NCs}(\mathrm{NCCM}+)$ exerted a more pronounced anabolic effect and induced higher notochord/ nucleus pulposus specific marker expression in CLCs than the secreted factors from dedifferentiated NCs ( $\mathrm{NCCM}-$ ), indicating that this was related to preservation of the NC phenotype (Arkesteijn et al., 2013).

\section{Proteomic analysis reveals many common proteins in porcine, canine and human NCCM}

Since previous findings indicated regenerative effects of porcine, canine and human NCCM on human CLCs (Bach et al., 2015), the main focus of the proteomic analysis of this study was on common proteins discovered in NCCM from all three species. A considerable part of the detected proteins consisted of ECM, e.g. proteoglycans, collagens and keratins, and organelle-derived proteins. However, specific growth factors, potentially responsible for NCCM's regenerative effect, were not identified, which is in contrast with previous studies in which CTGF was identified in canine (Erwin et al., 2006) and porcine (Gantenbein et al., 2014) NCCM. This discrepancy may be due to the method of NCCM generation. Whereas the previous studies produced NCCM from isolated NCs, in the current study, NCCM was generated from NC-rich NP tissue. Potential growth factors secreted by NCs may therefore be overshadowed by large quantities of proteins released during NP tissue incubation. In line with previous findings (Purmessur et al., 2011), however, clusterin and alpha-2-macroglobulin were detected in all the species' NCCM, and tenascin in human and canine NCCM. These matricellular proteins may have protective effects for NP cells. Furthermore, class 3 semaphorins were identified in canine (SEMA3C, SEMA3E) and porcine (SEMA3C) NCCM. SEMA3C is suggested to play a role in innervation and vascularisation of degenerated human IVDs and has been linked to back pain (Binch et al., 2015). The finding of SEMA3C and SEMA3E in canine and porcine NCCM derived from healthy NPs, however, may also support an inhibitory role of semaphorins in nerve and blood vessel growth (Bagnard et al., 1998).

The proteins in common to all three species and upstream bioinformatics analysis provide new insights into IVD (patho)physiology, including transcriptional gene regulation. For example, proteins related to transcription factor binding sites AP-1 and PAX4 were identified. AP-1 is a downstream target of the mitogenic activated protein (MAP) kinase signalling pathway and regulates chondrogenic differentiation (Seghatoleslami and Tuan, 2002). In healthy porcine, canine and human NP tissue, GAG synthesis may be regulated in an AP-1/growth factor-dependent manner, given that BMP2 and TGF- $\beta$ induced the expression of the GAG synthesis enzyme $\beta 1,3$-glucuronosyl transferase 1 in rat NP cells via amongst others - AP-1 (Hiyama et al., 2010). PAX4 has been mainly studied in the pancreas (Mathiyalagan et al., 2015; Napolitano et al., 2015), whereas its role in bone/ cartilaginous tissues is unexplored. PAX1 and PAX9, however, are known to be associated with axial and limb skeleton development (LeClair et al., 1999) and vertebral body and cartilage formation (Barnes et al., 1996). Furthermore, the current study also demonstrates that proteins related to $\mathrm{miR}-29 \mathrm{a} / \mathrm{b} / \mathrm{c}$ were present in porcine and human $\mathrm{NCCM}+$. The miR-29 family negatively regulates TGF- $\beta$ and canonical Wnt signalling (Le et al., 2016; Luna et al., 2011), exerts anti-fibrotic effects (He et al., 2013), and acts across development and progression of osteoarthritis (Le et al., 2016). In the IVD, the role of the miR-29 family has not been investigated yet, but based on knowledge from other tissues it could also be involved in ECM production.

Taken together, many common proteins were identified in porcine, canine and human NCCM. Mainly ECM and organelle-derived proteins, but no specific growth factors were detected. Furthermore, in porcine and human NCCM, platelet- and complement system-related proteins were identified. Possibly these proteins were identified as a result of blood contamination explained by the technically challenging harvesting of NP tissue, rather than being a biologically relevant finding. Hence, it may be beneficial for future studies to focus on comparative proteomic analysis of porcine, canine and human NCCM generated from isolated NCs, without interfering ECM proteins.

\section{Pelletable NCCM factors exert a moderate anabolic effect on canine CLCs}

Proteomic analysis revealed that $\mathrm{NCCM}+$ contained a considerable amount of membrane-bound vesicle proteins. In functional studies, the effect of NCCM-P (containing EVs and protein aggregates) was determined on CLCs. In bovine CLCs, the effect of porcine NCCM-P factors was negligible. In contrast, canine NCCM-P factors increased, in a concentration-dependent manner, the canine CLC GAG, GAG/DNA and collagen type II content compared with controls (although less pronounced than for the soluble factors). Also, canine NCCM-P decreased VEGF and increased KRT19 expression compared with controls, indicating that it inhibited angiogenesis (Cornejo et al., 2015) and induced a healthy NP-like phenotype (Minogue et al., 2010). The bovine CLCs were obtained from relatively healthy/early degenerated IVDs and the canine CLCs from degenerated IVDs, which may explain the difference in response, besides NCCM/CLC species differences.

In the present study, NCCM-P needed to be frozen, since canine NCCM donors were available at unpredictable moments. The effect of freezing EVs is controversial: previous studies demonstrated that EVs were relatively insensitive to freeze/thaw cycles (Lorincz et al., 2014; Witwer et al., 2013), whereas others showed the opposite (Dey-Hazra et al., 2010). The current study showed that at least $4 \mathrm{~d}$ of freezing at $-70{ }^{\circ} \mathrm{C}$ did not influence the biological activity of canine $\mathrm{NC}$-derived pelletable factors compared with non-frozen pelletable factors (kept at $4{ }^{\circ} \mathrm{C}$ ) from the same donor on canine CLC micro-aggregates. Besides long term freezing, also relatively hampered access to the pelletable factors could have accounted for the less 
pronounced effect of NCCM-P on the canine hydrogels and bovine alginate beads compared with the canine microaggregates.

Taken together, the present study demonstrates that the NCCM-P factors (protein aggregates and EVs) exerted a moderate concentration-dependent anabolic effect, but only on canine CLCs. While we cannot exclude that the absence of a biologic effect of EVs present in the NCCM-P may be related to the $100,000 \times g$ ultracentrifugation (Nordin et al., 2015), future studies should focus on the effect of different isolation protocols and different populations of purified NC-derived EVs, without interference of protein aggregates present in NCCM-P.

\section{Soluble porcine and canine NCCM factors exert anabolic effects on bovine and canine CLCs}

It appeared that most proteins remained in the soluble fraction of canine and porcine NCCM after ultracentrifugation. The effect of porcine NCCM-S on bovine CLCs was similar to that of $\mathrm{NCCM}+$, suggesting that porcine $\mathrm{NCCM}$ exerted its anabolic effect mainly through protein-based mechanisms. Also in the canine species, and the GAG content of NCCMS-treated hydrogels was rather similar to that of hydrogels treated with $\mathrm{NCCM}+$. However, the hydrogel appeared to have the propensity to bind the GAGs present in NCCM. Correcting for this property indicates that NCCM- may be even more active than NCCM+ or NCCM-S. However, this was not evident from the histological analysis. In our view, the amount of GAGs produced by the CLCs themselves cannot simply be calculated by correcting for the GAG content of empty hydrogels cultured in NCCM, because the incorporated ECM proteins likely changed the microenvironment and consequently affected GAG synthesis (Gilchrist et al., 2011; Inoue et al., 2005).

Generally, notochord/nucleus pulposus specific marker expression was higher after NCCM+ and NCCM-S than after NCCM-P treatment, indicating that NCCM+ and NCCM-S were better able to induce a healthy NP phenotype. Furthermore, ACAN and COL2A1 expression did not differ between NCCM-treated CLCs and controls, while ADAMTS5 and MMP13 gene expression levels were generally higher in NCCM+ and/or NCCM-Streated CLCs compared with other conditions. The latter is most probably related to ECM remodelling rather than catabolism, given that histological analysis points towards a stronger anabolic effect of NCCM+ and NCCM-S than NCCM-P and NCCM-. In NCCM+ and NCCM-S, more pericellular GAGs were observed, suggesting that the CLCs synthesised these GAGs themselves. Also collagen type II deposition was highest after NCCM+ and NCCM-S treatment, again indicating that both porcine and canine NCCM exerted their anabolic effects mainly through proteins. Since no blocking experiment was performed, however, it is difficult to discern if one or combination of factors are responsible for the effects of NCCM.

\section{Conclusions}

The present study demonstrates an anabolic cross-species effect of porcine and canine NCCM+ on bovine and canine CLCs, respectively. Especially on bovine CLCs, a pronounced effect of the soluble NCCM fraction (NCCM-S; peptides, proteins) was found, without an appreciable effect of the pelletable NCCM fraction (NCCM-P; protein aggregates, EVs). However, NCCM-P exerted a moderate anabolic effect on canine CLCs, although the culture system used precludes firm conclusions. Thus, although porcine and canine NCCM exerted their anabolic effects mainly through soluble factors, also the pelletable NCCM factors showed moderate regenerative potential. Although the regenerative potential of NCCM-P should not be overlooked, future studies should focus on unravelling the protein-based regenerative mechanism from NCCM produced from isolated NCs, e.g. by NCCM fractionation and pathway blocking studies.

\section{Acknowledgements}

This work was funded by AOSpine International (SRN2011_11) and the Dutch Arthritis Foundation (LLP22). The authors would like to thank Willem de Jong for help with the execution of experiments and Anita Krouwels for supplying human IVDs. We wish to confirm that there are no known conflicts of interest associated with this publication and there has been no significant financial support for this work that could have influenced its outcome.

\section{References}

Abbott RD, Purmessur D, Monsey RD, Iatridis JC (2012) Regenerative potential of TGFbeta3 + Dex and notochordal cell conditioned media on degenerated human intervertebral disc cells. J Orthop Res 30: 482-488.

Anderson HC, Mulhall D, Garimella R (2010) Role of extracellular membrane vesicles in the pathogenesis of various diseases, including cancer, renal diseases, atherosclerosis, and arthritis. Lab Invest 90: 1549-1557.

Arkesteijn IT, Potier E, Ito K (2013) Maintaining notochordal phenotype. Global Spine Congress 2013, Hong Kong.

Arkesteijn IT, Smolders LA, Spillekom S, Riemers FM, Potier E, Meij BP, Ito K, Tryfonidou MA (2015) Effect of coculturing canine notochordal, nucleus pulposus and mesenchymal stromal cells for intervertebral disc regeneration. Arthritis Res Ther 17: 60 .

Bach FC, Willems N, Penning LC, Ito K, Meij BP, Tryfonidou MA (2014) Potential regenerative treatment strategies for intervertebral disc degeneration in dogs. BMC Vet Res 10: 3 .

Bach FC, de Vries SA, Krouwels A, Creemers LB, Ito K, Meij BP, Tryfonidou MA (2015) The species-specific regenerative effects of notochordal cellconditioned medium on chondrocyte-like cells derived from degenerated human intervertebral discs. Eur Cell Mater 30: 132-146.

Bagnard D, Lohrum M, Uziel D, Puschel AW, Bolz J (1998) Semaphorins act as attractive and repulsive 
guidance signals during the development of cortical projections. Development 125: 5043-5053.

Barnes GL, Hsu CW, Mariani BD, Tuan RS (1996) Chicken Pax-1 gene: structure and expression during embryonic somite development. Differentiation 61: 13-23.

Benneker LM, Andersson G, Iatridis JC, Sakai D, Hartl R, Ito K, Grad S (2014) Cell therapy for intervertebral disc repair: advancing cell therapy from bench to clinics. Eur Cell Mater 27: 5-11.

Benz K, Stippich C, Osswald C, Gaissmaier C, Lembert N, Badke A, Steck E, Aicher WK, Mollenhauer JA (2012) Rheological and biological properties of a hydrogel support for cells intended for intervertebral disc repair. BMC Musculoskelet Disord 13: 54.

Binch AL, Cole AA, Breakwell LM, Michael AL, Chiverton N, Creemers LB, Cross AK, Le Maitre CL (2015) Class 3 semaphorins expression and association with innervation and angiogenesis within the degenerate human intervertebral disc. Oncotarget 6: 18338-18354.

Bolstad BM (2016) Package 'preprocessCore': a collection of pre-processing functions Version 1.33.0.

Carlson M (2016) GO.db: A set of annotation maps describing the entire Gene Ontology. R package version 3.2.2.

Chen H (2015) Package 'VennDiagram': Generate high-resolution Venn and Euler plots.

Chen J, Bardes EE, Aronow BJ, Jegga AG (2009) ToppGene Suite for gene list enrichment analysis and candidate gene prioritization. Nucleic Acids Res 37: W305311.

Cheung KM, Karppinen J, Chan D, Ho DW, Song YQ, Sham P, Cheah KS, Leong JC, Luk KD (2009) Prevalence and pattern of lumbar magnetic resonance imaging changes in a population study of one thousand forty-three individuals. Spine 34: 934-940.

Cornejo MC, Cho SK, Giannarelli C, Iatridis JC, Purmessur D (2015) Soluble factors from the notochordalrich intervertebral disc inhibit endothelial cell invasion and vessel formation in the presence and absence of pro-inflammatory cytokines. Osteoarthritis Cartilage 23: 487-496.

de Graaf EL, Giansanti P, Altelaar AF, Heck AJ (2014) Single-step enrichment by Ti4 ${ }^{+}$-IMAC and label-free quantitation enables in-depth monitoring of phosphorylation dynamics with high reproducibility and temporal resolution. Mol Cell Proteomics 13: 2426-2434.

de Vries SA, Potier E, van Doeselaar M, Meij BP, Tryfonidou MA, Ito K (2015) Conditioned medium derived from notochordal cell-rich nucleus pulposus tissue stimulates matrix production by canine nucleus pulposus cells and bone marrow-derived stromal cells. Tissue Eng Part A 21: 1077-1084.

de Vries SA, van Doeselaar M, Meij BP, Tryfonidou MA, Ito K (2016) The stimulatory effect of notochordal cell-conditioned medium in a nucleus pulposus explant culture. Tissue Eng Part A 22: 103-110.

Dey-Hazra E, Hertel B, Kirsch T, Woywodt A, Lovric S, Haller H, Haubitz M, Erdbruegger U (2010) Detection of circulating microparticles by flow cytometry: influence of centrifugation, filtration of buffer, and freezing. Vasc Health Risk Manag 6: 1125-1133.
Durinck S, Spellman PT, Birney E, Huber W (2009) Mapping identifiers for the integration of genomic datasets with the R/Bioconductor package biomaRt. Nat Protoc 4: 1184-1191.

Erwin WM, Ashman K, O’Donnel P, Inman RD (2006) Nucleus pulposus notochord cells secrete connective tissue growth factor and up-regulate proteoglycan expression by intervertebral disc chondrocytes. Arthritis Rheum 54: 3859-3867.

Farndale RW, Sayers CA, Barrett AJ (1982) A direct spectrophotometric microassay for sulfated glycosaminoglycans in cartilage cultures. Connect Tissue Res 9: 247-248.

Gantenbein B, Calandriello E, Wuertz-Kozak K, Benneker LM, Keel MJ, Chan SC (2014) Activation of intervertebral disc cells by co-culture with notochordal cells, conditioned medium and hypoxia. BMC Musculoskelet Disord 15: 422.

Gilchrist CL, Darling EM, Chen J, Setton LA (2011) Extracellular matrix ligand and stiffness modulate immature nucleus pulposus cell-cell interactions. PLoS One 6: e27170.

Guo JF, Jourdian GW, MacCallum DK (1989) Culture and growth characteristics of chondrocytes encapsulated in alginate beads. Connect Tissue Res 19: 277-297.

He Y, Huang C, Lin X, Li J (2013) MicroRNA-29 family, a crucial therapeutic target for fibrosis diseases. Biochimie 95: 1355-1359.

Hiyama A, Gogate SS, Gajghate S, Mochida J, Shapiro IM, Risbud MV (2010) BMP-2 and TGF-beta stimulate expression of beta1,3-glucuronosyl transferase 1 (GlcAT-1) in nucleus pulposus cells through AP1, TonEBP, and Sp1: role of MAPKs. J Bone Miner Res 25: 1179-1190.

Inoue T, Nakamura T, Ikeda T, Takagi K (2005) Effect of extracellular matrix protein on the rate of proteoglycan synthesis in rabbit intervertebral disc cells. J Spinal Disord Tech 18: 52-57.

Korecki CL, Taboas JM, Tuan RS, Iatridis JC (2010) Notochordal cell conditioned medium stimulates mesenchymal stem cell differentiation toward a young nucleus pulposus phenotype. Stem Cell Res Ther 1: 18.

Le LT, Swingler TE, Crowe N, Vincent TL, Barter MJ, Donell ST, Delany AM, Dalmay T, Young DA, Clark IM (2016) The microRNA-29 family in cartilage homeostasis and osteoarthritis. J Mol Med 94: 583-596.

LeClair EE, Bonfiglio L, Tuan RS (1999) Expression of the paired-box genes Pax-1 and Pax-9 in limb skeleton development. Dev Dyn 214: 101-115.

Lorincz AM, Timar CI, Marosvari KA, Veres DS, Otrokocsi L, Kittel A, Ligeti E (2014) Effect of storage on physical and functional properties of extracellular vesicles derived from neutrophilic granulocytes. J Extracell Vesicles 3: 25465 .

Luna C, Li G, Qiu J, Epstein DL, Gonzalez P (2011) Cross-talk between miR-29 and transforming growth factor-betas in trabecular meshwork cells. Invest Ophthalmol Vis Sci 52: 3567-3572.

Luoma K, Riihimaki H, Luukkonen R, Raininko R, Viikari-Juntura E, Lamminen A (2000) Low back pain in relation to lumbar disc degeneration. Spine 25: 487-492. 
Mahmoudabady M, Niazmand S, Shafei MN, McEntee $\mathrm{K}$ (2013) Investigation of apoptosis in a canine model of chronic heart failure induced by tachycardia. Acta Physiol Hung 100: 435-444.

Malda J, Boere J, van de Lest CH, van Weeren PR, Wauben MH (2016) Extracellular vesicles - new tool for joint repair and regeneration. Nat Rev Rheumatol 12: 243 249.

Marino F, Cristobal A, Binai NA, Bache N, Heck AJ, Mohammed S (2014) Characterization and usage of the EASY-spray technology as part of an online 2D SCX-RP ultra-high pressure system. Analyst 139: 6520-6528.

Mathiyalagan P, Keating ST, Al-Hasani K, El-Osta A (2015) Epigenetic-mediated reprogramming of pancreatic endocrine cells. Antioxid Redox Signal 22: 1483-1495.

Minogue BM, Richardson SM, Zeef LA, Freemont AJ, Hoyland JA (2010) Characterization of the human nucleus pulposus cell phenotype and evaluation of novel marker gene expression to define adult stem cell differentiation. Arthritis Rheum 62: 3695-3705.

Muir P, Danova NA, Argyle DJ, Manley PA, Hao Z (2005) Collagenolytic protease expression in cranial cruciate ligament and stifle synovial fluid in dogs with cranial cruciate ligament rupture. Vet Surg 34: 482-490.

Napolitano T, Avolio F, Courtney M, Vieira A, Druelle N, Ben-Othman N, Hadzic B, Navarro S, Collombat P (2015) Pax4 acts as a key player in pancreas development and plasticity. Semin Cell Dev Biol 44: 107-114.

Nordin JZ, Lee Y, Vader P, Mager I, Johansson HJ, Heusermann W, Wiklander OP, Hallbrink M, Seow Y, Bultema JJ, Gilthorpe J, Davies T, Fairchild PJ, Gabrielsson S, Meisner-Kober NC, Lehtio J, Smith CI, Wood MJ, El Andaloussi S (2015) Ultrafiltration with size-exclusion liquid chromatography for high yield isolation of extracellular vesicles preserving intact biophysical and functional properties. Nanomedicine 11: 879-883.

Potier E, de Vries S, van Doeselaar M, Ito K (2014) Potential application of notochordal cells for intervertebral disc regeneration: an in vitro assessment. Eur Cell Mater 28: $68-80$.

Purmessur D, Schek RM, Abbott RD, Ballif BA, Godburn KE, Iatridis JC (2011) Notochordal conditioned media from tissue increases proteoglycan accumulation and promotes a healthy nucleus pulposus phenotype in human mesenchymal stem cells. Arthritis Res Ther 13: R81.

Purmessur D, Cornejo MC, Cho SK, Hecht AC, Iatridis JC (2013) Notochordal cell-derived therapeutic strategies for discogenic back pain. Global Spine J 3: 201-218.

Sakai D, Andersson GB (2015) Stem cell therapy for intervertebral disc regeneration: obstacles and solutions. Nat Rev Rheumatol 11: 243-256.

Sakai D, Grad S (2015) Advancing the cellular and molecular therapy for intervertebral disc disease. Adv Drug Deliv Rev 84: 159-171.

Scholz B, Kinzelmann C, Benz K, Mollenhauer J, Wurst H, Schlosshauer B (2010) Suppression of adverse angiogenesis in an albumin-based hydrogel for articular cartilage and intervertebral disc regeneration. Eur Cell Mater 20: 24-36.

Seghatoleslami MR, Tuan RS (2002) Cell density dependent regulation of AP-1 activity is important for chondrogenic differentiation of C3H10T1/2 mesenchymal cells. J Cell Biochem 84: 237-248.

van der Vlist EJ, Nolte-'t Hoen EN, Stoorvogel W, Arkesteijn GJ, Wauben MH (2012) Fluorescent labeling of nano-sized vesicles released by cells and subsequent quantitative and qualitative analysis by high-resolution flow cytometry. Nat Protoc 7: 1311-1326.

Witwer KW, Buzas EI, Bemis LT, Bora A, Lasser C, Lotvall J, Nolte-'t Hoen EN, Piper MG, Sivaraman S, Skog J, Thery C, Wauben MH, Hochberg F (2013) Standardization of sample collection, isolation and analysis methods in extracellular vesicle research. J Extracell Vesicles 2: 10.3402/jev.v2i0.20360.

\section{Discussion with Reviewers}

Reviewer II: Notochordal cells (NCs) were associated with the occurrence of chordoma, a mostly benign form of spine cancer. Chordomas are thought to arise from remnants of the embryonic notochord. Thus, the lack of NC in adults seems to be highly relevant for a healthy development. The authors assumedly aim for a therapeutic drug isolated from the secretome of the $\mathrm{NC}$, the so-called conditioned medium (NCCM). Cancer cells often influence their neighbouring cells by a specific signalling. What would be the authors' vision to deliver such a signalling molecule to the intervertebral disc and what risks do the authors see for clinical application?

Authors: Since chordomas are thought to arise from the embryonic notochord, the application of notochord-/ notochordal cell-derived factors could theoretically induce chordoma formation. However, it is unclear which initiating mechanisms are crucial for chordoma development when notochordal remnants persist. Also, the prevalence of chordoma in humans (and mice) is very low ( 1 in 1,000,000 people) (Lawson and Harfe, 2015). In line with this, in the clinics we (almost) never see tumours arising from the nucleus pulposus in nonchondrodystrophic dogs, and these dogs do retain their NCs until late in life (Smolders et al., 2013) and can develop several other types of cancer. This altogether suggests that the vast majority of notochord cells or their remnants do not result in disease. Nonetheless, when screening for potential regenerative NC-secreted factors, factors that are known to be associated with cancer formation should be carefully investigated in this respect.

\section{Additional References}

Lawson L, Harfe BD (2015) Notochord to nucleus pulposus transition. Curr Osteoporos Rep 13: 336-341.

Smolders LA, Bergknut N, Grinwis GC, Hagman R, Lagerstedt AS, Hazewinkel HA, Tryfonidou MA, Meij BP (2013) Intervertebral disc degeneration in the dog. Part 2: chondrodystrophic and non-chondrodystrophic breeds. Vet J 195: 292-299.

Editor's note: The Scientific Editor responsible for this paper was Mauro Alini. 